NIST Technical Note 1679

\title{
Repeatability and reproducibility of compression strength measurements conducted according to ASTM E9
}

William E. Luecke

$\mathrm{Li} \mathrm{Ma}$

Stephen M. Graham

Matthew A. Adler

http://dx.doi.org/10.6028/NIST.TN.1679

National Institute of Standards and Technology U.S. Department of Commerce 


\title{
NIST Technical Note 1679
}

\section{Repeatability and reproducibility of compression strength measurements conducted according to ASTM E9}

\author{
William E. Luecke \\ $\mathrm{Li} \mathrm{Ma}$ \\ Metallurgy Division \\ Materials Science and Engineering Laboratory \\ Stephen M. Graham \\ United States Naval Academy \\ Mechanical Engineering Department \\ Matthew A. Adler \\ Marshall Space Flight Center \\ Jacobs ESTS Group/ICRC \\ http://dx.doi.org/10.6028/NIST.TN.1679
}

September 2009

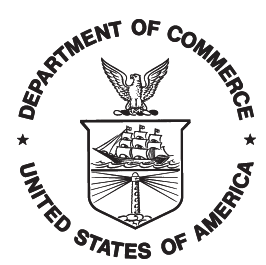

U.S. Department of Commerce Gary Locke, Secretary

National Institute of Standards and Technology Patrick D. Gallagher, Director 
Certain commercial entities, equipment, or materials may be identified in this document in order to describe an experimental procedure or concept adequately. Such identification is not intended to imply recommendation or endorsement by the National Institute of Standards and Technology, nor is it intended to imply that the entities, materials, or equipment are necessarily the best available for the purpose.

National Institute of Standards and Technology Technical Note 1679 Natl. Inst. Stand. Technol. Technical Note 1679, 40 pages (September 2009) http://dx.doi.org/10.6028/NIST.TN.1679 


\begin{abstract}
Ten commercial laboratories participated in an interlaboratory study to establish the repeatability and reproducibility of compression strength tests conducted according to ASTM International Standard Test Method E9. The test employed a cylindrical aluminum AA2024-T351 test specimen. Participants measured elastic modulus and $0.2 \%$ offset yield strength, $Y S(0.2 \%$ offset $)$, using an extensometer attached to the specimen. The repeatability and reproducibility of the yield strength measurement, expressed as coefficient of variations were $c v_{r}=0.011$ and $c v_{R}=0.020$ The reproducibility of the test across the laboratories was among the best that has been reported for uniaxial tests. The reported data indicated that using diametrally opposed extensometers, instead of a single extensometer, doubled the precision of the test method. Laboratories that did not lubricate the ends of the specimen measured yield stresses and elastic moduli that were smaller than those measured in laboratories that lubricated the specimen ends. A finite element analysis of the test specimen deformation for frictionless and perfect friction could not explain the discrepancy, however. The modulus measured from stress-strain data were reanalyzed using a technique that finds the optimal fit range, and applies several quality checks to the data. The error in modulus measurements from stress-strain curves generally increased as the fit range decreased to less than $40 \%$ of the stress range.
\end{abstract}

Keywords: compression, testing, ILS, ASTM, E9, yield strength, elastic modulus 


\section{Introduction}

Compression testing is a conceptually simple method to establish the uniaxial stress-strain and mechanical behavior of materials. Because the test specimens can be right circular cylinders, they are easy to fabricate. The short gauge length of the test specimen sometimes makes it the only possible geometry for establishing some uniaxial properties, for example those normal to the plane of a plate. Compression tests can also be used to establish the strength of brittle materials [1, 2] that would be difficult to grip in tension. Kuhn [3] and Chait [4] have reviewed the methods for compression testing, and have demonstrated that although the test is conceptually simple, the user must overcome many experimental difficulties to translate the measured load and displacement curves into accurate stress-strain behavior.

Much of the literature, see Table 1, on implementing the compression test focuses on tests to large strains $[5,7,8,10,12,13,17,18]$, to establish strain-hardening behavior beyond the strains at which tension test specimens neck. Other studies are devoted to modelling processes such as upsetting [5, 14, 15, 17, 18]. A common theme in these and other studies has been to quantify the effects of friction [18, 7, 12] and barreling [5, 11, 17. 9] on interpreting the stress-strain behavior of the test specimen, or finding the optimal lubricant [4, 6, 12, 13].

ASTM International standard test method E9, [2] first established in 1924, is a consensus standard for conducting compression tests to establish the strength of materials. It contains methods for testing cylindrical test specimens as well as methods for testing sheets with lateral support. The standard contains requirements for calibrating and qualifying the testing machine including extensometers, and aligning the fixtures and test specimen. It recommends, but does not require, specific test specimen geometries and lubricants. In addition, it suggests several fixture designs. It does not require the use of an extensometer in contact with the test specimen to measure strain, and most studies that reference E9 infer the test specimen strain and stress from the displacement of the actuator.

Although the first version of E9 was released eight decades ago, its precision has never been formally evaluated, as required [19]. Such evaluations require a formal interlaboratory study, which can benefit both end user and testing laboratories. Users need the results of interlaboratory tests to determine the uncertainty that should be associated with the value of a material parameter obtained using a test method. Laboratories that employ test methods use interlaboratory studies to identify the deficiencies in their test methods and improve their implementation of them.

This manuscript reports the results of an interlaboratory study to establish the precision of ASTM International standard test method E9 for determining the yield strength

and elastic modulus in compression. The results of this study were incorporated into the Precision and Bias statement of E9 in 2009. This report goes beyond the research report [20] that documents the calculation of the precision by comparing the results to other interlaboratory studies of uniaxial test methods, Sec. 4.1. analyzing some of the possi- 
Table 1: Summary of literature that analyzes the compression test.

\begin{tabular}{|c|c|c|c|c|}
\hline Reference & Content & $e_{\max }$ & Materials & Lubricant \\
\hline Banerjee, 1985[5] & $\mathrm{b}$ & 1.6 & $\mathrm{Al}$ & $\begin{array}{l}\text { teflon, } \mathrm{MoS}_{2} \text {, } \\
\text { oil, none }\end{array}$ \\
\hline Carter, 1985[6] & $\mathrm{F}$ & 0.35 & $\mathrm{Al}$ & $\mathrm{MoS}_{2}$, none \\
\hline Chait, 1975[4] & $\mathrm{r}$ & NA & & \\
\hline Cook, 1945[7] & $\mathrm{f}$ & 0.7 & $\mathrm{Cu}$ & none \\
\hline Gunasekera, 1982[8] & $\mathrm{f}$ & 1.2 & 1022 steel & teflon \\
\hline Hsü, 1969[9] & bfF & NA & $\mathrm{Cu}$ & teflon \\
\hline Kamaluddin, 2007[10] & $\mathrm{F}$ & 0.8 & $\mathrm{Al}$ & grease \\
\hline Kobayashi, 1970[11] & $\mathrm{b}$ & 1.4 & 1040 steel & graphite \\
\hline Lovato, 1992[12] & $\mathrm{f}$ & 1 & $\begin{array}{l}\mathrm{Al}, \mathrm{Nb} \text {, brass, } \\
\text { steel }\end{array}$ & $\begin{array}{l}\mathrm{MoS}_{2} \text {, teflon, } \\
\mathrm{BN} \text {, none }\end{array}$ \\
\hline Male, 1966[13] & $\mathrm{f}$ & 0.8 & $\mathrm{Al}, \mathrm{Ti}$, brass & $\begin{array}{l}\text { graphite, } \\
\text { lanolin, paraffin }\end{array}$ \\
\hline Mescall, 1983[14] & $\mathrm{F}$ & NA & 4340 steel & \\
\hline Papirno, 1983[15] & 0 & NA & steel & teflon \\
\hline Ray, 1983[16] & $\mathrm{f}$ & NA & steel & teflon \\
\hline Schey, 1982[17] & $\mathrm{b}$ & 1 & $\begin{array}{l}1020 \text { steel, } 6061 \\
\mathrm{Al}\end{array}$ & $\mathrm{MoS}_{2}$, teflon \\
\hline Woodward, 1977[18] & $\mathrm{f}$ & 1.2 & steel & teflon \\
\hline Key & & & \multicolumn{2}{|c|}{ Key to content of reference } \\
\hline$e_{\max }:$ maximum strain $\mathrm{i}$ & in test & & \multicolumn{2}{|c|}{ b: barreling analysis } \\
\hline \multirow[t]{3}{*}{ NA : not available } & & & \multicolumn{2}{|l|}{ f: friction analysis } \\
\hline & & & \multicolumn{2}{|c|}{ F: finite element analysis } \\
\hline & & & \multicolumn{2}{|l|}{$\mathrm{r}$ : review article } \\
\hline
\end{tabular}


Table 2: List of participants in this study.

Participant

URL

AADFW, Inc, Euless, Tx

http://www.aadfwinc.com

Alcoa, Pittsburgh, Pa

http://www.alcoa.com

Exova, Glendale Hts, IL

http://www.exova.com

Dickson Testing Company Inc.,

South Gate, $\mathrm{Ca}$

Imperial College Mechanical

Engr., London, England

MAR-TEST, Inc. (Cincinnati),

Cincinnati, Oh

MAR-TEST, Inc. (Stuart), Stuart,

$\mathrm{Fl}$

Metcut Research Inc., Cincinnati,

$\mathrm{Oh}$

Stork Climax Research Services,

Wixom, MI

http://www.dicksontesting.com/

http://www.imperial.ac.uk/

http://www.mar-test.com/

http://www.mar-test.com/

http://www.metcut.com

http://www.storksmt.com/crs

Westmoreland Mechanical Testing, http://www.wmtr.com

Youngstown, $\mathrm{Pa}$

ble sources for the variability, Sec. 4.2, and presenting a method to evaluate the elastic modulus measured in the test, Sec. 4.3 .

\section{Experimental Procedure}

This interlaboratory study followed the methods of ASTM E691 [21], and uses statistical terms in accord with ASTM E177 [22].

\subsection{Participants}

Using the ASTM International [23] and American Association for Laboratory Accreditation [24] laboratory directories, the organizers contacted and discussed the interlaboratory study with twenty-five possible laboratory participants. From this original list thirteen laboratories agreed and were able to participate, and ten ultimately completed the test program, Table 2 .

\subsection{Instructions and method}

The participants followed ASTM Standard Test Method E9 [2] to establish the elastic modulus, $E$, and $0.2 \%$ offset yield strength, $Y S(0.2 \%$ offset $)$. At the time of the study, the version of E9 in use was E9-89a, but the only non-editorial difference between E9$89 \mathrm{a}$ and the current version, E9-09 was the addition of the precision statement to the latter, 
which was the purpose of the interlaboratory study. The participants also returned electronic traces of the stress-strain curves to the organizers. All compression fixtures were required to be qualified according to ASTM E9 Section 6.6 [2] using at least five of the supplied test specimens, unless the participant had already qualified the test setup according to E9 Section 6.6. The participants conducted the compression tests using at least one extensometer at a nominal strain rate of $d e / d t=0.005 \mathrm{~min}^{-1}=8.33 \times 10^{-5} \mathrm{~s}^{-1}$. No laboratory reported strain measured from actuator displacement. Each participant reported ten items as required in sections 10.1.1-10.1.9 and 10.1.13 of standard method E9: Material (test specimen ID), configuration description, test specimen dimensions as tested, fixture and lubricant description, testing machine description, speed of testing (required in section 8.7; report actual value), stress-strain diagram, modulus of elasticity, $E$, yield strength, $Y S(0.2 \%$ offset $)$, and any anomalies.

\subsection{Test Specimen}

The material tested was aluminum alloy AA2024-T351, which is solution heat-treated and stress-relieved by controlled stretching. It was supplied as a plate with thickness, $t=22.2 \mathrm{~mm}(0.875 \mathrm{in})$, from which the organizers cut and distributed test specimen blanks, which were distributed throughout the plate. Figure 1 describes the location of the test specimens in the original plate and their numbering scheme. Only test specimens in rows 1 and 2 were used in this study. Test specimens number 1-50 came from row 1; test specimens 51-100 came from row 2. Figure 2 shows the test specimen with dimensions and tolerances. The drawing provided to the participants showed the dimensions in U.S.Customary units, rather than SI units. Participants machined their own test specimens from sawed blanks that the organizers supplied.

Test specimens were tested with the loading axis transverse to the rolling direction in the plane of the plate, the so-called long-transverse ("LT") orientation, Mil-Handbook5J [25] Figure 1.4.12.3(a). The test specimen ID takes the form "LT-NN-L-X" where "LT" identifies the orientation relative to the rolling direction, "NN" identifies the test specimen number (1-250), "L" identifies the laboratory that received the test specimen blank (A-K) and " $\mathrm{X}$ " identifies the test order of the test specimen at a given laboratory.

\subsection{Compression fixtures}

The participants used a variety of loading fixtures, some of which involved a sub-press mounted in the testing machine to improve alignment. Others used adjustable platens that were aligned and then locked. Three laboratories used diametrically opposed extensometers instead of a single extensometer. No laboratory reported strain from actuator displacement. Table 3 describes the specimen fixturing, alignment capability, number of extensometers, and the lubricant used in each laboratory.

\section{Results}

\subsection{Stress-strain behavior}

Figure 3 plots the engineering stress-strain curves by laboratory. For convenience, com- 


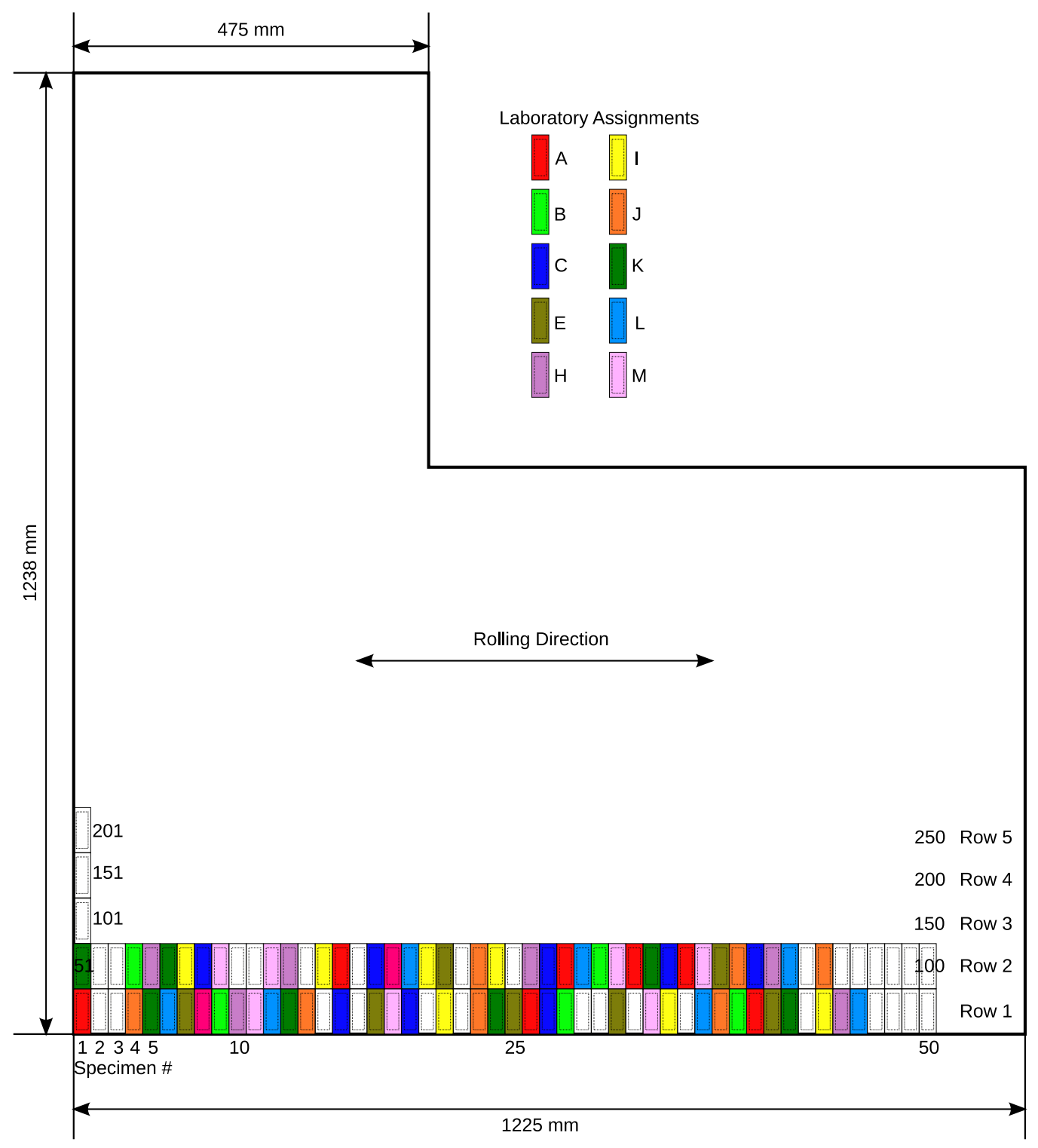

Figure 1: Schematic of the location of test specimen blanks in the original plate. 
Table 3: Descriptions of the compression setup, extensometers and gauge lengths, $G$, and lubricants for all laboratories.

\begin{tabular}{|c|c|c|c|}
\hline Lab & test setup & Extensometer & Lubricant \\
\hline A & No sub-press & $\begin{array}{l}\text { Two, opposed, } \\
\text { class B-1 } \\
G=25.4 \mathrm{~mm}\end{array}$ & Not reported \\
\hline B & Sub-press & $\begin{array}{l}\text { Single, class not } \\
\text { reported } \\
G=12.7 \mathrm{~mm}\end{array}$ & Molybdenum disulfide \\
\hline $\mathrm{C}$ & $\begin{array}{l}\text { No sub-press, no spherical } \\
\text { seat }\end{array}$ & $\begin{array}{l}\text { Single, class } \\
\text { not-reported } \\
G=25.4 \mathrm{~mm}\end{array}$ & None \\
\hline $\mathrm{E}$ & sub-press & $\begin{array}{l}\text { Single, class B-1 } \\
G=25.4 \mathrm{~mm}\end{array}$ & Teflon tape \\
\hline $\mathrm{H}$ & No sub-press & $\begin{array}{l}\text { Single class B-2, } \\
G=12.7 \mathrm{~mm}\end{array}$ & Molybdenum disulfide \\
\hline I & No sub-press & $\begin{array}{l}\text { Two opposed, } \\
\text { class B- } 2, \\
G=25.4 \mathrm{~mm}\end{array}$ & Not reported \\
\hline $\mathrm{J}$ & $\begin{array}{l}\text { Precision ground } \\
\text { sub-press, aligned to } \\
\text { closer tolerance than } \\
\text { required for specimen, no } \\
\text { spherical seat }\end{array}$ & $\begin{array}{l}\text { Two opposed, } \\
\text { class B-1 } \\
G=25.4 \mathrm{~mm}\end{array}$ & None \\
\hline $\mathrm{K}$ & $\begin{array}{l}\text { No sub-press. Platens } \\
\text { aligned, shimmed and } \\
\text { then locked. No spherical } \\
\text { seat }\end{array}$ & $\begin{array}{l}\text { Single, class B-2, } \\
G=12.7 \mathrm{~mm}\end{array}$ & Molybdenum disulfide \\
\hline $\mathrm{L}$ & Sub-press & $\begin{array}{l}\text { Single, class B-2 } \\
G=25.4 \mathrm{~mm}\end{array}$ & WD-40 \\
\hline $\mathrm{M}$ & $\begin{array}{l}\text { Compression platens } \\
\text { mounted in aligned } \\
\text { hydraulic grips }\end{array}$ & $\begin{array}{l}\text { Single, class B- } 2 \text {, } \\
G \text { not reported }\end{array}$ & None \\
\hline
\end{tabular}




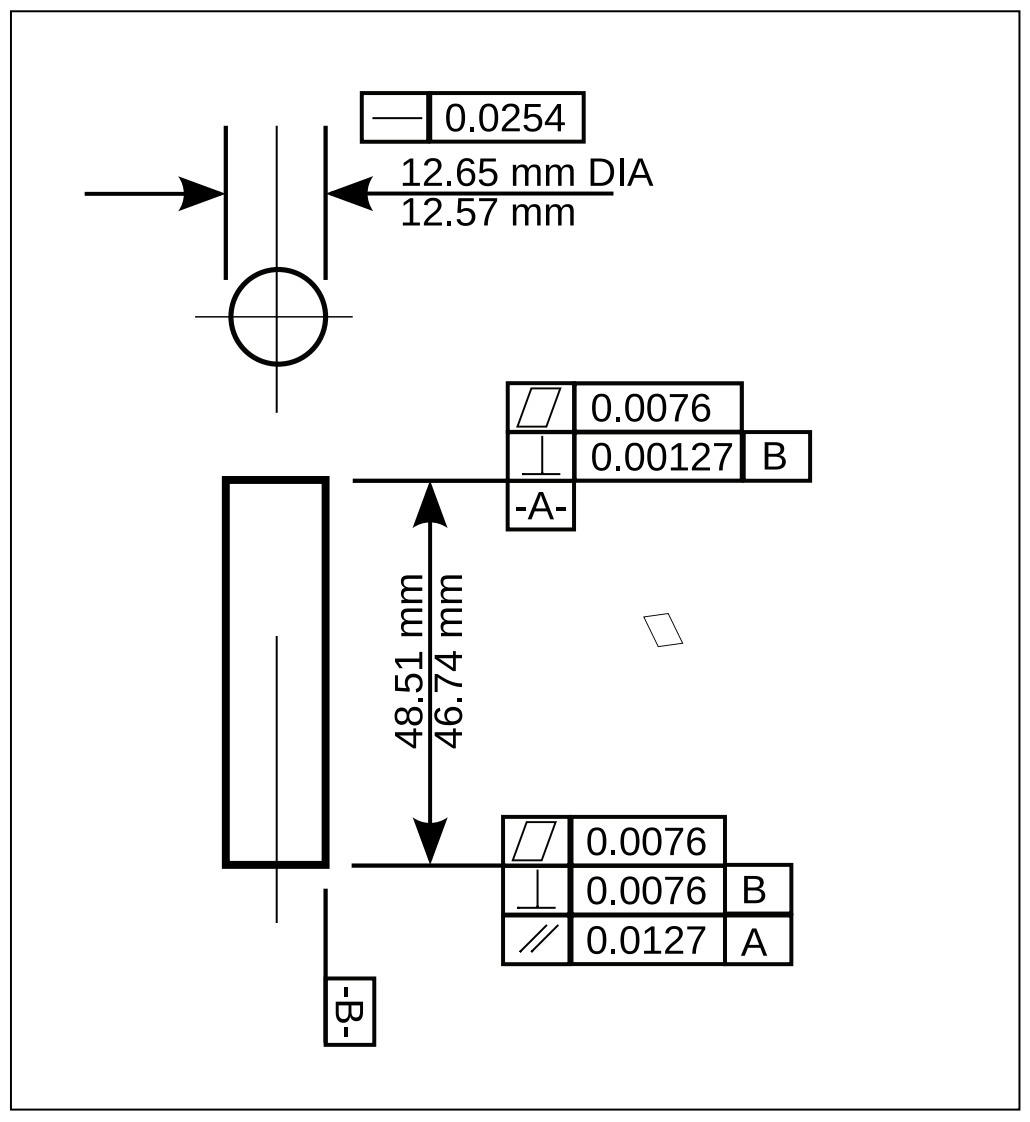

Figure 2: Dimensions of the test specimen used.

pressive strains and stresses are plotted as positive, rather than negative, values. In each case the stress-strain curve was shifted along the strain axis so that a linear fit to the stressstrain $(S-e)$ data in the range $(50<S<175) \mathrm{MPa}$ intercepts the origin. Figure 4 presents four views of the same stress-strain curves over different strain ranges.

Table 4 summarizes the reported modulus, $E$, and yield strength, $Y S(0.2 \%$ offset $)$, for the laboratories. Figure 5 plots the reported elastic modulus, $E$, by laboratory. Figure 6 plots the reported $0.2 \%$ offset yield strength, $Y S(0.2 \%$ offset $)$, by laboratory.

\subsection{Testing rates}

Figure 7 plots the strain as a function of time for the laboratories that reported time data. The interlaboratory instructions did not specify a control mode for the test. Four laboratories $(\mathrm{C}, \mathrm{H}, \mathrm{K}, \mathrm{L})$ conducted the test in strain control from the extensometer signal, as indicated from the constant slope of the strain-time plot, Figure 7. Three laboratories (A,E,J) conducted the test in position control, as indicated from the changing slope in the strain-time plot. Figure 8 plots the strain rates in the elastic and plastic portions of the 


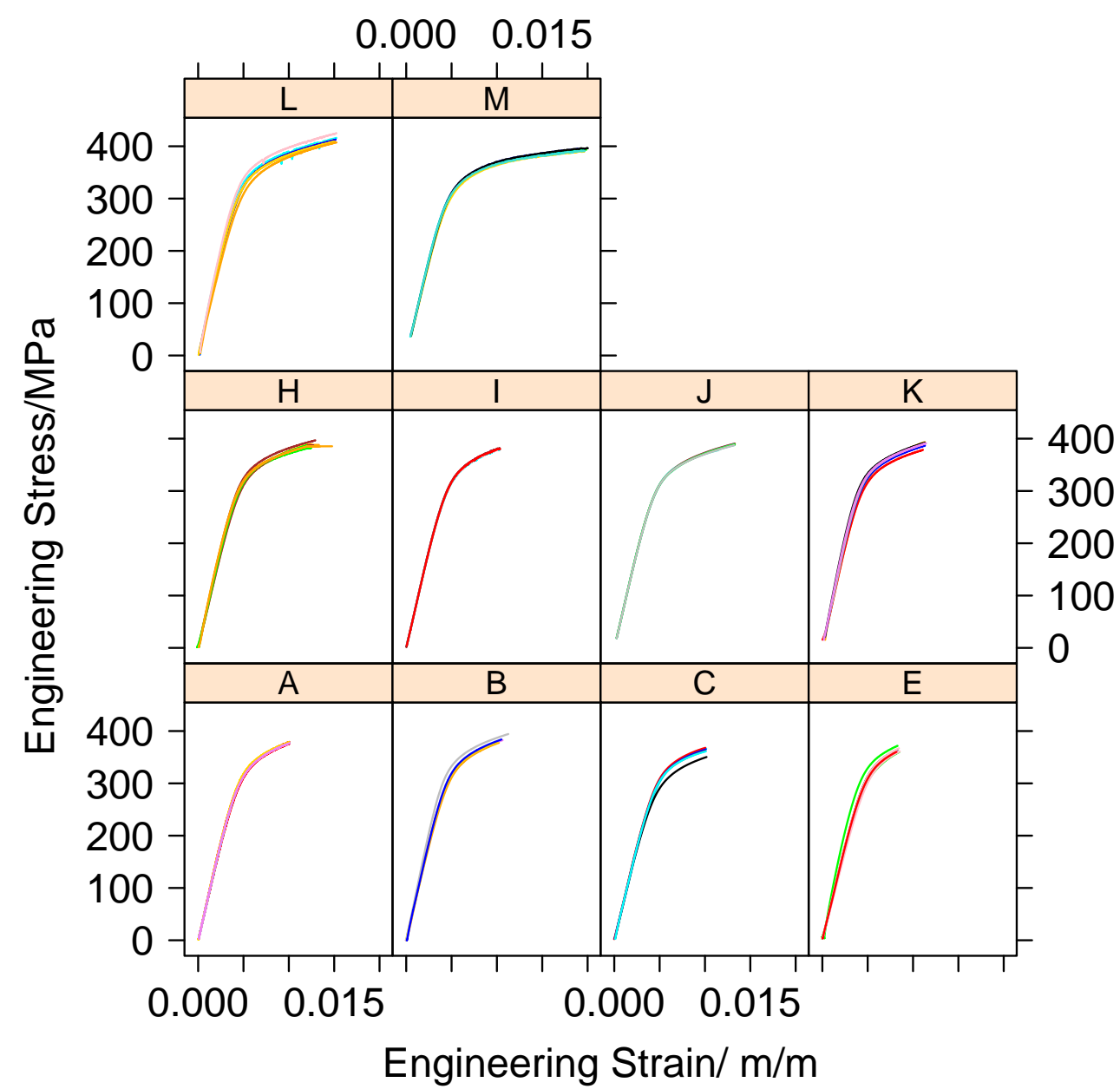

Figure 3: Engineering stress-strain curves. 


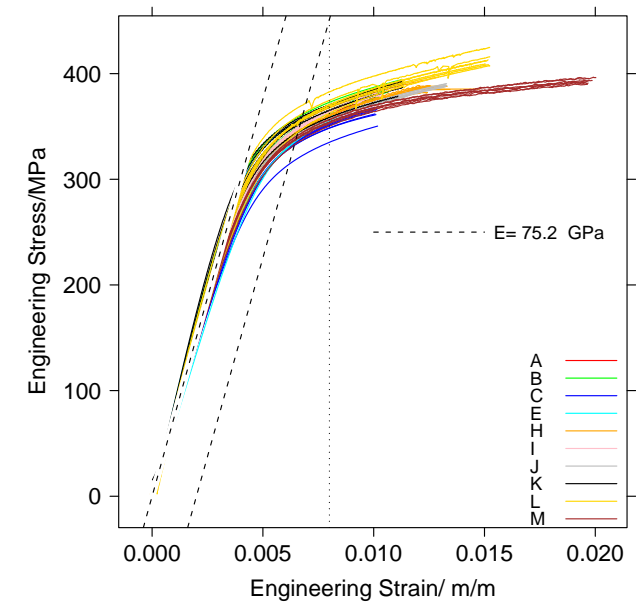

(a) Complete

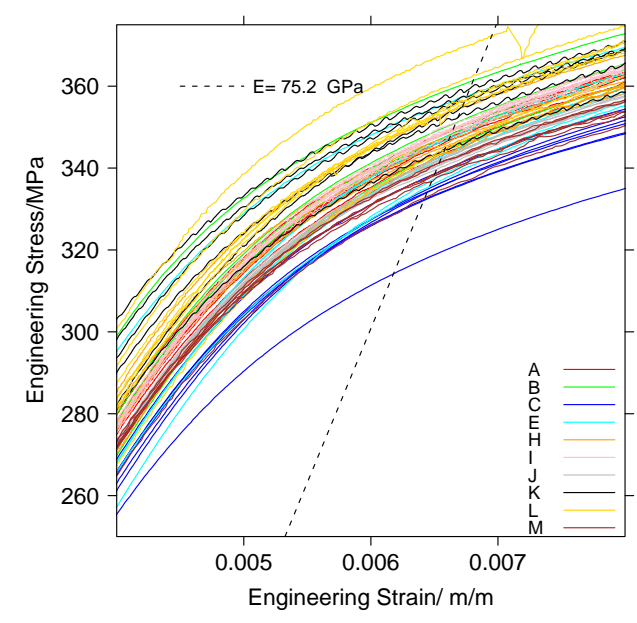

(c) Yield behavior

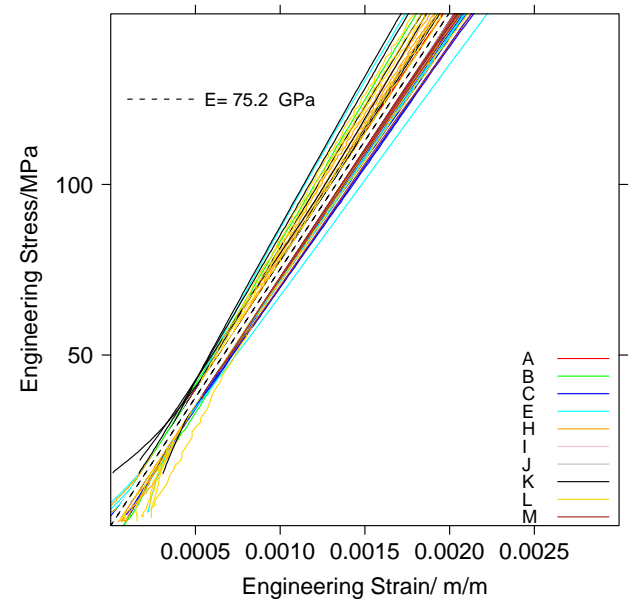

(b) Low-strain behavior

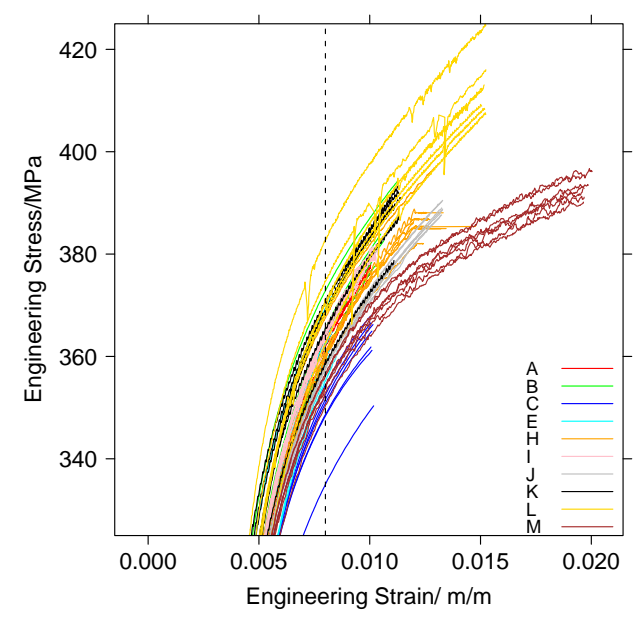

(d) Plastic behavior

Figure 4: Engineering stress-strain curves: (a) complete behavior, (b) low-strain behavior, (c) yield behavior, and (d) plastic behavior. Dashed lines show the accepted value for the modulus of 2024-T351, $E=75.2 \mathrm{GPa}$, the $0.2 \%$ offset yield strength determination, and the $e=0.008$ total elongation. 


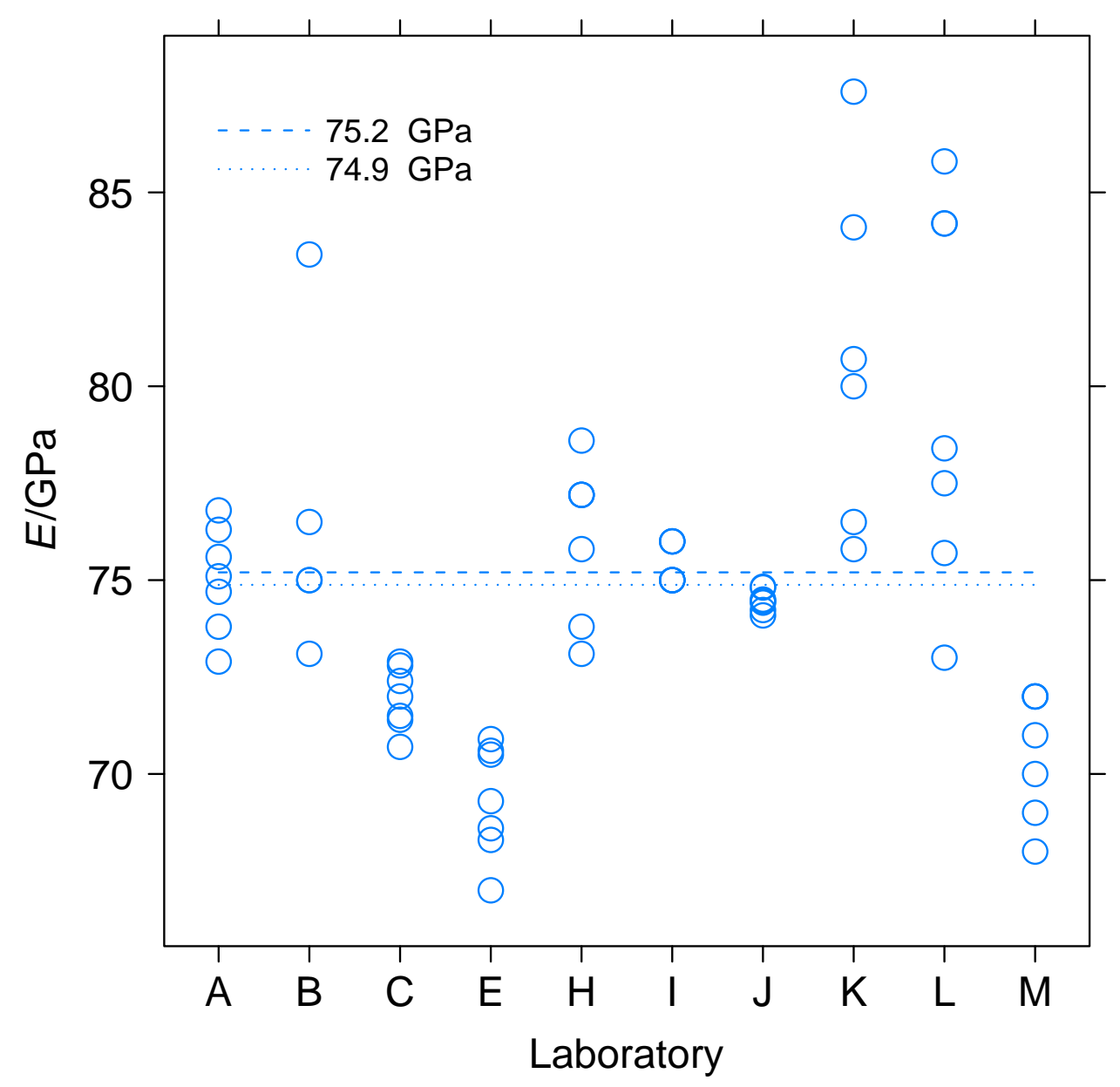

Figure 5: Reported elastic modulus, $E$. Dashed lines show the average reported modulus and a commonly accepted value of the modulus ( $E=75.2 \mathrm{GPa}$ ) from Mil-HDBK-5J [25] and the average of all the measurements, $E=74.9 \mathrm{GPa}$. 


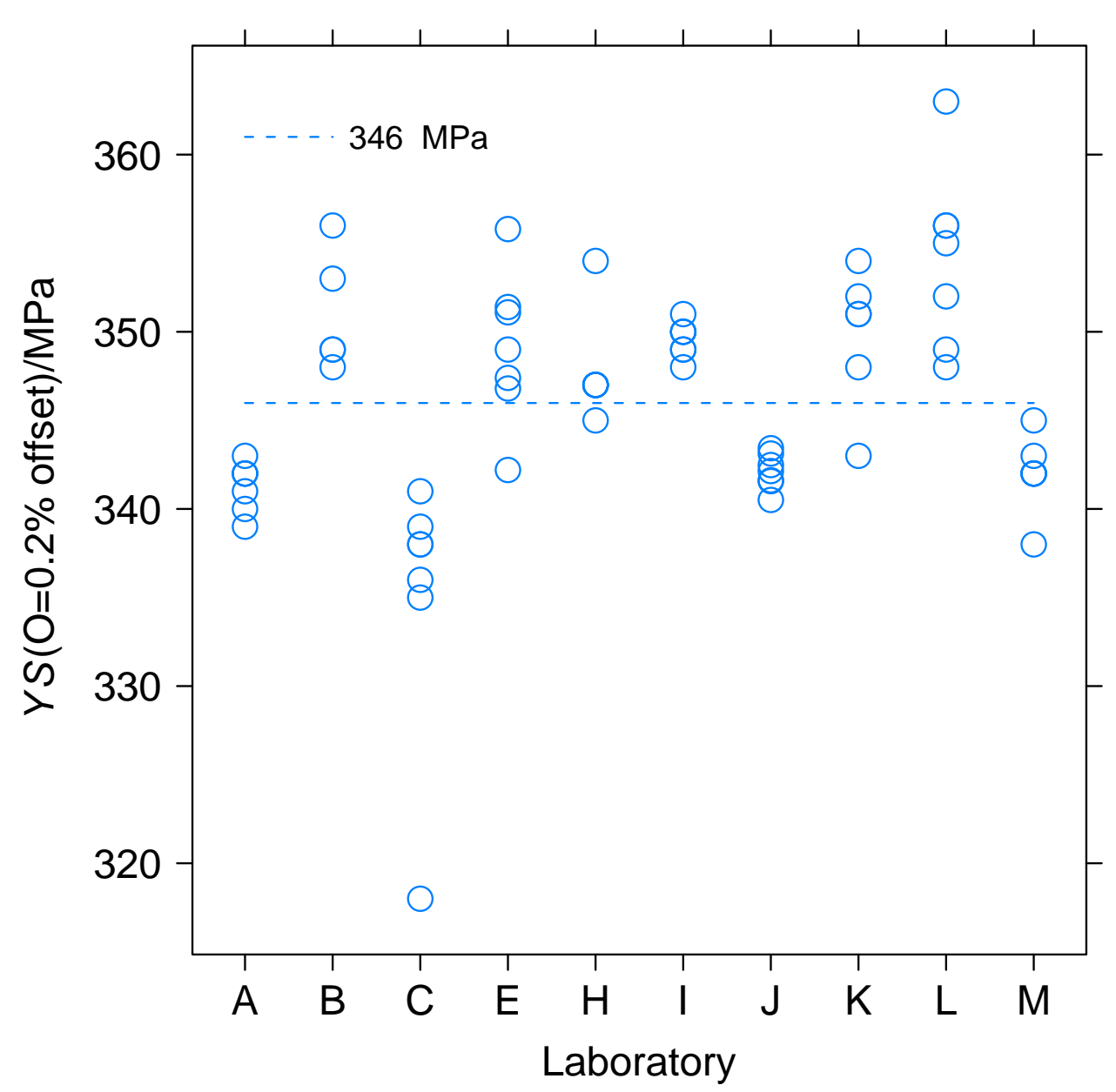

Figure 6: Reported $0.2 \%$ offset yield strength, $Y S(0.2 \%$ offset $)$. The dashed line is the average of the results from all laboratories. 


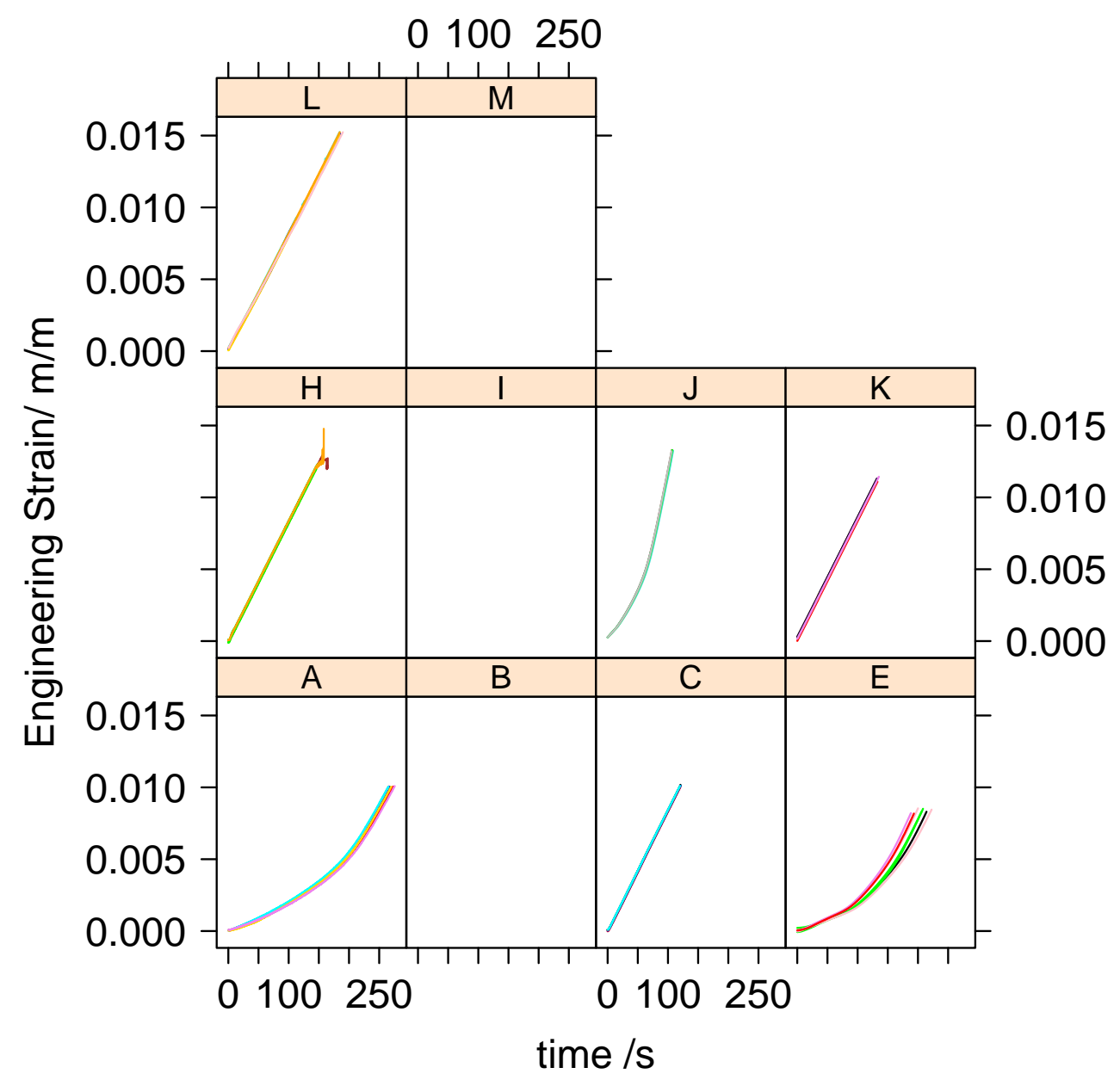

Figure 7: Reported strain as a function of time. 
Table 4: Reported data

\begin{tabular}{|c|c|c|c|c|c|c|c|c|c|c|c|}
\hline $\mathrm{Lab}$ & Sample & $\begin{array}{r}E \\
\mathrm{GPa}\end{array}$ & $\begin{array}{r}Y S \\
\mathrm{MPa}\end{array}$ & $\mathrm{Lab}$ & Sample & $\begin{array}{r}E \\
\mathrm{GPa}\end{array}$ & $\begin{array}{r}Y S \\
\mathrm{MPa}\end{array}$ & $\mathrm{Lab}$ & Sample & $\begin{array}{r}E \\
\mathrm{GPa}\end{array}$ & $\begin{array}{r}Y S \\
\mathrm{MPa}\end{array}$ \\
\hline $\mathrm{A}$ & LT-85 & 75.6 & 339.0 & $\mathrm{H}$ & LT-10 & 77.2 & 345.0 & K & LT-24 & 75.8 & 343.0 \\
\hline A & LT-1 & 72.9 & 340.0 & $\mathrm{H}$ & LT-44 & 73.8 & 347.0 & K & LT-42 & 80.7 & 348.0 \\
\hline A & LT-40 & 76.8 & 341.0 & $\mathrm{H}$ & LT-55 & 73.1 & 347.0 & K & LT-51 & 87.6 & 351.0 \\
\hline A & LT-26 & 75.1 & 342.0 & $\mathrm{H}$ & LT-63 & 77.2 & 347.0 & K & LT-56 & 84.1 & 351.0 \\
\hline A & LT-66 & 73.8 & 342.0 & $\mathrm{H}$ & LT-76 & 75.8 & 347.0 & K & LT-5 & 80.0 & 352.0 \\
\hline A & LT-78 & 74.7 & 342.0 & $\mathrm{H}$ & LT-91 & 77.2 & 347.0 & K & LT-13 & 76.5 & 354.0 \\
\hline A & LT- 82 & 76.3 & 343.0 & $\mathrm{H}$ & LT-19 & 78.6 & 354.0 & K & LT-83 & NA & NA \\
\hline B & LT- 28 & 73.1 & 348.0 & I & LT-43 & 75.0 & 348.0 & $\mathrm{~L}$ & LT-79 & 73.0 & 348.0 \\
\hline B & LT-39 & 76.5 & 349.0 & I & LT-57 & 76.0 & 349.0 & $\mathrm{~L}$ & LT-45 & 84.2 & 349.0 \\
\hline B & LT-54 & 75.0 & 349.0 & I & LT-65 & 75.0 & 349.0 & $\mathrm{~L}$ & LT-69 & 78.4 & 352.0 \\
\hline B & LT-9 & 75.0 & 353.0 & I & LT-21 & 76.0 & 350.0 & $\mathrm{~L}$ & LT-12 & 84.2 & 355.0 \\
\hline B & LT-80 & 83.4 & 356.0 & I & LT-34 & 75.0 & 350.0 & $\mathrm{~L}$ & LT-36 & 75.7 & 356.0 \\
\hline C & LT-68 & 72.0 & 318.0 & I & LT-74 & 75.0 & 350.0 & $\mathrm{~L}$ & LT-6 & 77.5 & 356.0 \\
\hline $\mathrm{C}$ & LT- 84 & 72.8 & 335.0 & I & LT-70 & 76.0 & 351.0 & $\mathrm{~L}$ & LT-92 & 85.8 & 363.0 \\
\hline C & LT-90 & 71.5 & 336.0 & $\mathrm{~J}$ & LT-4 & 74.5 & 340.5 & $\mathrm{M}$ & LT-18 & 69.0 & 338.0 \\
\hline C & LT-16 & 72.4 & 338.0 & $\mathrm{~J}$ & LT-89 & 74.2 & 341.6 & $\mathrm{M}$ & LT-11 & 72.0 & 342.0 \\
\hline $\mathrm{C}$ & LT-77 & 71.4 & 338.0 & $\mathrm{~J}$ & LT-94 & 74.4 & 341.6 & $\mathrm{M}$ & LT-59 & 71.0 & 342.0 \\
\hline $\mathrm{C}$ & LT-27 & 70.7 & 339.0 & $\mathrm{~J}$ & LT-73 & 74.5 & 342.1 & $\mathrm{M}$ & LT-62 & 70.0 & 342.0 \\
\hline C & LT-58 & 72.9 & 341.0 & $\mathrm{~J}$ & LT-37 & 74.8 & 342.5 & $\mathrm{M}$ & LT-86 & 72.0 & 342.0 \\
\hline E & LT-25 & 68.3 & 342.2 & $\mathrm{~J}$ & LT-23 & 74.8 & 343.1 & $\mathrm{M}$ & LT-33 & 72.0 & 343.0 \\
\hline $\mathrm{E}$ & LT-31 & 67.0 & 346.8 & $\mathrm{~J}$ & LT-14 & 74.1 & 343.4 & M & LT-81 & 68.0 & 345.0 \\
\hline $\mathrm{E}$ & LT-87 & 69.3 & 347.4 & & & & & & & & \\
\hline E & LT-71 & 68.6 & 349.0 & & & & & & & & \\
\hline $\mathrm{E}$ & LT-17 & 70.5 & 351.1 & & & & & & & & \\
\hline E & LT-8 & 70.9 & 351.4 & & & & & & & & \\
\hline $\mathrm{E}$ & LT-41 & 70.6 & 355.8 & & & & & & & & \\
\hline
\end{tabular}

stress-strain curves calculated by linear regression. The plastic strain rate was calculated for strains greater than the strain at the $0.2 \%$ offset yield strength: $e_{\text {YSO02 }}<e<e_{\max }$. The elastic strain rate was calculated in the range $0<e<\left(e_{\mathrm{YS} 002}-0.002\right)$. Laboratory $\mathbf{J}$ conducted the test in position control and set the elastic strain rate close to the specified value.

\section{Analysis and discussion}

\subsection{Expected variability}

Table 5 summarizes the mean and standard deviation, sd, and coefficient of variation, $c v$, of the reported $n$ measurements of the elastic moduli and yield strengths. Table 6 defines the statistical parameters used in this section. 


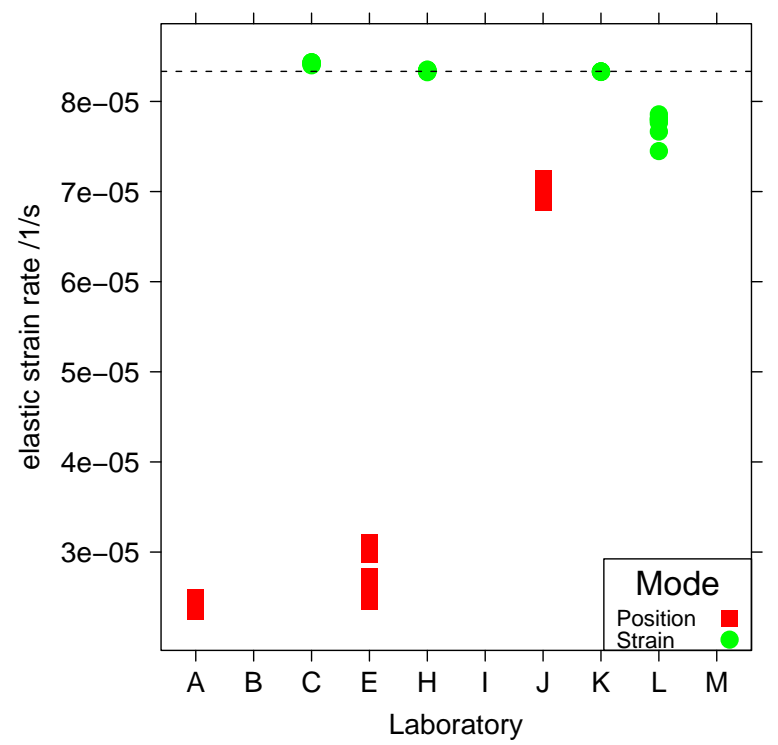

(a) elastic strain rate

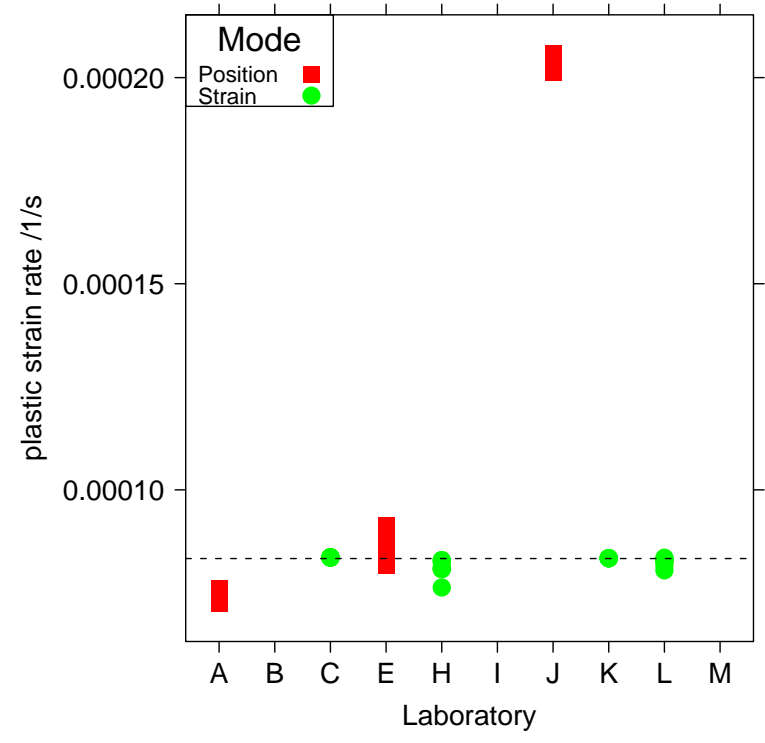

(b) plastic strain rate

Figure 8: Calculated (a) elastic and (b) plastic strain rates for laboratories that reported time data. Symbols differentiate between position-control and strain-control tests. Dashed line indicates the requested rate, $d e / d t=8.33 \times 10^{-5} 1 / \mathrm{s}$. 
Table 5: Summary statistics for the modulus and yield strength data.

\begin{tabular}{cccccccc}
\hline Lab & $n$ & $\bar{E}$ & $\mathrm{sd}(E)$ & $c v(E)$ & $\bar{Y} S$ & $\mathrm{sd}(Y S)$ & $c v(Y S)$ \\
& & $\mathrm{GPa}$ & $\mathrm{GPa}$ & & $\mathrm{MPa}$ & $\mathrm{MPa}$ & \\
\hline $\mathrm{A}$ & 7 & 75.0 & 1.4 & 0.018 & 341.3 & 1.4 & 0.004 \\
$\mathrm{~B}$ & 5 & 76.6 & 4.0 & 0.052 & 351.0 & 3.4 & 0.010 \\
$\mathrm{C}$ & 7 & 72.0 & 0.8 & 0.011 & 335.0 & 7.7 & 0.023 \\
$\mathrm{E}$ & 7 & 69.3 & 1.4 & 0.021 & 349.1 & 4.3 & 0.012 \\
$\mathrm{H}$ & 7 & 76.1 & 2.0 & 0.026 & 347.7 & 2.9 & 0.008 \\
$\mathrm{I}$ & 7 & 75.4 & 0.5 & 0.007 & 349.6 & 1.0 & 0.003 \\
$\mathrm{~J}$ & 7 & 74.5 & 0.3 & 0.004 & 342.1 & 1.0 & 0.003 \\
$\mathrm{~K}$ & 7 & 80.8 & 4.5 & 0.056 & 349.8 & 3.9 & 0.011 \\
$\mathrm{~L}$ & 7 & 79.8 & 4.9 & 0.062 & 354.1 & 5.1 & 0.014 \\
$\mathrm{M}$ & 7 & 70.6 & 1.6 & 0.023 & 342.0 & 2.1 & 0.006 \\
\hline
\end{tabular}

Note: $Y S=Y S(0.2 \%$ offset $)$

\begin{tabular}{cccccc}
\hline Parameter & Grand Average & $s_{r}$ & $c v_{r}$ & $s_{R}$ & $c v_{R}$ \\
\hline$E$ & $\overline{\bar{E}}=75.0 \mathrm{GPa}$ & $2.7 \mathrm{GPa}$ & 0.036 & $4.4 \mathrm{GPa}$ & 0.059 \\
$Y S(0.2 \%$ offset $)$ & $\bar{Y} S(0.2 \%$ offset $)=346.2 \mathrm{MPa}$ & $3.8 \mathrm{MPa}$ & 0.011 & $6.8 \mathrm{MPa}$ & 0.020 \\
\hline
\end{tabular}

Table 6 defines the parameters. Because laboratory B tested only five specimens instead of seven, the mean values shown in Figures 5, 6, 10, and 12 differ from the Grand Average, also known as the average of cell averages, Table 6 . Eq. 2

The results of an interlaboratory study contain variability that arises within a given laboratory and variability that arises between laboratories. The terms repeatability and the reproducibility, denoted by subscripted " $r$ " and " $R$," are often used to differentiate between these sources [22]. In a general sense, repeatability characterizes the ability of an individual laboratory to repeat measurements, while reproducibility characterizes the ability of an individual laboratory to achieve the global mean or accepted value. For example, if the results from an individual laboratory are tightly grouped, their repeatability is high, but their mean value may still deviate significantly from the accepted value, in which case their reproducibility is low.

Both the variability in the material and the variability of the test method influence the repeatability. The excellent repeatability of the measurements for both $E$ and $Y S(0.2 \%$ offset) in laboratories A, I, and J , Table 5, shows that the material variability in this study is quite low, and therefore the implementation of the test method by the individual laboratories is the major contributor to repeatability.

Figure 9 and Table 7 compare the results for repeatability and reproducibility for this study to the results of other interlaboratory studies of tensile tests at room [26, 27] and 
Table 6: Definitions of repeatability and reproducibility statistics.

\begin{tabular}{|c|c|c|}
\hline Formula & Description & \\
\hline$n$ & number of tests in a laboratory, $n \approx 7$ & \\
\hline$p$ & number of laboratories, $p=10$ & \\
\hline$Y_{i j}$ & individual test result in lab $j$ & \\
\hline & $1<i<n \quad ; \quad 1<j<p$ & \\
\hline $\bar{Y}_{j}=\frac{1}{n} \sum_{i=1}^{n} Y_{i j}$ & average test result in lab $j$ (cell average) & $(1)$ \\
\hline$\overline{\bar{Y}}=\frac{1}{p} \sum_{j=1}^{p} \bar{Y}_{j}$ & average of cell averages (grand average) & $(2)$ \\
\hline$s_{j}=\sqrt{\frac{1}{n-1} \sum_{i=1}^{n}\left(Y_{i j}-\bar{Y}_{j}\right)^{2}}$ & standard deviation measured in lab $j$ & (3) \\
\hline$s_{r}=\sqrt{\frac{1}{p}} \sum_{j=1}^{P}\left(s_{j}\right)^{2}$ & repeatability (within-lab) standard deviation & $(4)$ \\
\hline$c v_{r}=\frac{s_{r}}{\overline{\bar{Y}}}$ & coefficient of variation within laboratories & $(5)$ \\
\hline 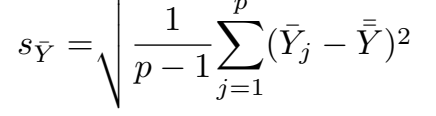 & standard deviation of cell averages & $(6)$ \\
\hline$s_{R}=\sqrt{s_{\bar{Y}}^{2}+s_{r}^{2}\left(\frac{n-1}{n}\right)}$ & reproducibility standard deviation ((between-lab) & $(7)$ \\
\hline$c v_{R}=\frac{s_{R}}{\overline{\bar{Y}}}$ & coefficient of variation between laboratories & $(8)$ \\
\hline
\end{tabular}

elevated temperatures [28] to establish the $0.2 \%$ offset yield strength, $Y S(0.2 \%$ offset $)$. In Figure 9 the within-laboratory and between-laboratory standard deviations, $s_{r}$, Eq. 4 , and $s_{R}$, Eq. 7, see Table 6, are divided by the mean value and expressed as their respective coefficients of variation, $c v_{r}, \mathrm{Eq} .5$, and $c v_{R}, \mathrm{Eq} .8$.

The repeatability coefficient of variation of the yield strength measurements in this study, derived from the average of the standard deviations of the individual laboratories, is $c v_{r}=0.0111$, Eq. 5, while the coefficient of variation of the reproducibility, $c v_{R}=0.0197$, Eq. 8, is about twice as large. The repeatability and reproducibility of compression tests established in this study are among the best measurements of all reported uniaxial measurements [26, 27, 28]. 


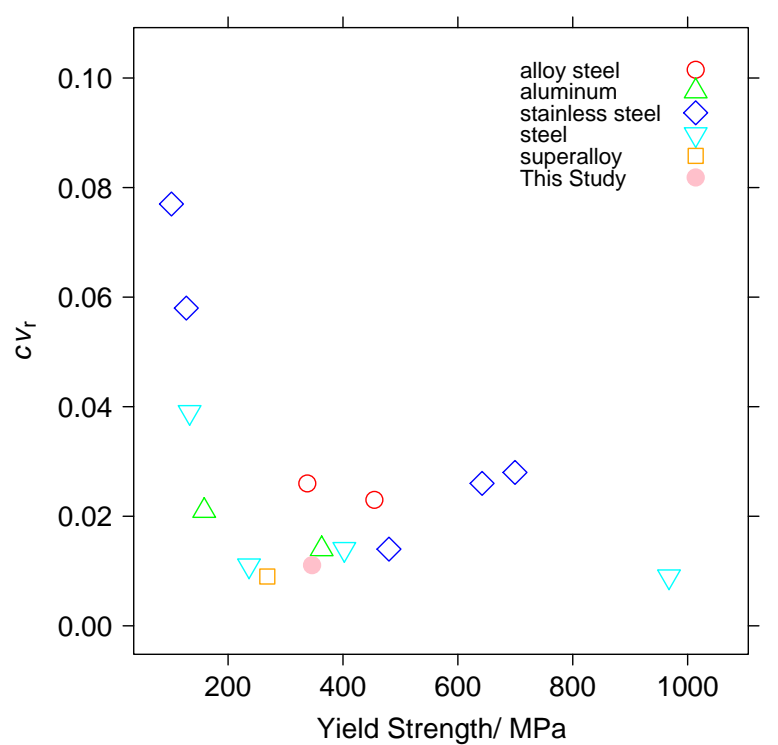

(a) Repeatability

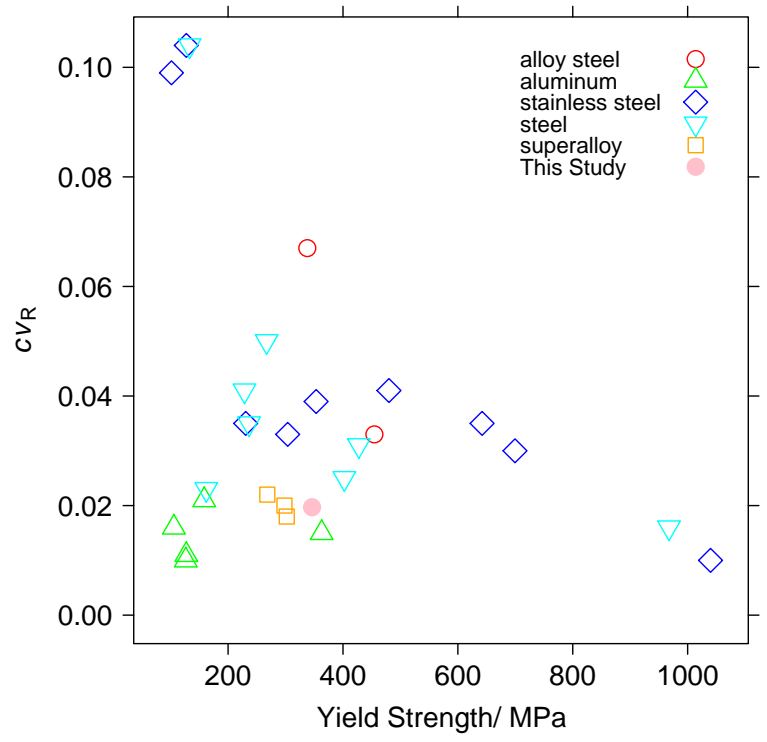

(b) Reproducibility

Figure 9: Literature data [26, 28, 27] on (a) repeatability (within-laboratory) and (b) reproducibility (between-laboratory) of yield strength, $Y S(0.2 \%$ offset). Table 7 summarizes the data. 
Table 7: Literature data [28, 26, 27] for repeatability and reproducibility in mechanical testing.

\begin{tabular}{llcccc}
\hline Source & \multicolumn{1}{c}{ Material } & $\begin{array}{c}\mathrm{T} \\
{ }^{\circ} \mathrm{C}\end{array}$ & $\begin{array}{c}\mathrm{MPa} \\
\mathrm{MPa}\end{array}$ & $c v_{r}$ & $c v_{R}$ \\
\hline & & 20.0 & 158.4 & 0.0210 & 0.0210 \\
\hline$[26]$ & EC-H19 aluminum & 20.0 & 362.9 & 0.0140 & 0.0150 \\
{$[26]$} & 2024-T351 aluminum & 20.0 & 402.4 & 0.0140 & 0.0250 \\
{$[26]$} & AISI A105 steel & 20.0 & 480.1 & 0.0140 & 0.0410 \\
{$[26]$} & SS316 stainless steel & 20.0 & 268.3 & 0.0090 & 0.0220 \\
{$[26]$} & Inconel 600 & 20.0 & 967.5 & 0.0090 & 0.0160 \\
{$[26]$} & SAE 51410 steel & 20.0 & 105.7 & NA & 0.0160 \\
{$[27]$} & AA5754 Al & 20.0 & 126.4 & NA & 0.0100 \\
{$[27]$} & AA51802-O & 20.0 & 127.2 & NA & 0.0110 \\
{$[27]$} & AA6016-T4 & 20.0 & 162.0 & NA & 0.0230 \\
{$[27]$} & DX56, low-carbon steel & 20.0 & 228.6 & NA & 0.0410 \\
{$[27]$} & HR3 steel plate & 20.0 & 267.1 & NA & 0.0500 \\
{$[27]$} & ZStE 180 steel & 20.0 & 427.6 & NA & 0.0310 \\
{$[27]$} & S355 steel plate & 20.0 & 230.7 & NA & 0.0350 \\
{$[27]$} & SS316L stainless steel & 20.0 & 303.8 & NA & 0.0330 \\
{$[27]$} & X2CrNi18-10 stainless steel & 20.0 & 353.3 & NA & 0.0390 \\
{$[27]$} & X2CrNiMo18-10 & 20.0 & 1039.9 & NA & 0.0100 \\
{$[27]$} & 30NiCrMo16 high strength steel & 20.0 & 302.1 & NA & 0.0180 \\
{$[27]$} & Nimonic 75 CRM 661 & 20.0 & 298.1 & NA & 0.0200 \\
{$[27]$} & Nimonic 75 CRM 661 & 316.0 & 127.3 & 0.0580 & 0.1040 \\
{$[28]$} & SS304 stainless steel & 316.0 & 236.4 & 0.0110 & 0.0350 \\
{$[28]$} & Low-carbon steel & 316.0 & 454.7 & 0.0230 & 0.0330 \\
{$[28]$} & 2.25 Cr 1Mo steel & 316.0 & 699.5 & 0.0280 & 0.0300 \\
{$[28]$} & A286 stainless steel & 593.0 & 101.4 & 0.0770 & 0.0990 \\
{$[28]$} & SS304 stainless steel & 593.0 & 133.0 & 0.0390 & 0.1040 \\
{$[28]$} & Low-carbon steel & 593.0 & 337.9 & 0.0260 & 0.0670 \\
{$[28]$} & 2.2.5Cr 1Mo ferritic steel & 593.0 & 642.2 & 0.0260 & 0.0350 \\
{$[28]$} & A286 stainless steel & 20.0 & 346.2 & 0.0111 & 0.0197 \\
\hline This study & Al 2024-T351 & & & & \\
\hline & & & &
\end{tabular}

Notes:

$Y S=Y S(0.2 \%$ offset $)$

$\mathrm{NA}=$ data not available 


\subsection{Effect of test method implementation}

Because the laboratories were free to implement the test method in different ways, while still complying with the standard, their results can be used to learn about the effect of different aspects of test method on the measurement. In particular, the results can be examined to determine the effects of the number of extensometers and lubrication on the quality of the measurement.

\subsubsection{Effect of number of extensometers}

Some laboratories used a single extensometer, while others used two opposed extensometers to measure the strain. Figure 10 plots the reported modulus and yield strength for the laboratories, grouped by the number of extensometers used in the determination. The three laboratories, A, I, J, with the best repeatability and reproducibility of $E$ and $Y S(0.2 \%$ offset) are the only ones that used a system of two-opposed extensometers instead of a single extensometer. In addition, the measured elastic modulus in these three laboratories was the closest to the accepted [25] value $E=75.2 \mathrm{GPa}$, Figure $10 \mathrm{a}$. Note that the repeatability of the modulus and yield strength from the labs that used a single extensometer is worse (i.e. larger variability), but also that for an individual laboratory, the values usually all lie above or below the grand average. Using two extensometers will tend to average the effect of non-axial loading, since during bending, one side of the test specimen will be displaced more, and the other less. Because the values for an individual, single-extensometer laboratory are usually displaced to one side of the global mean value points toward the alignment of the compression fixture, rather than machining of the test specimen as the source of the non-axiality. If the ends of the test specimen were not parallel, the measured values would tend to encompass the mean value, because no special relationship exists between the test specimen and the loading fixture. Conversely, the extensometer is usually mounted on the test specimen with a fixed relation to the orientation of loading fixture, so bending induced by a slightly misaligned loading fixture is always in the same geometric relation to the extensometer, which will tend to always over- or under-estimate the strain.

\subsubsection{Effect of Lubricant}

The standard allows the laboratory to choose whether to lubricate the ends of the test specimen during the test. Figure 11 shows the engineering stress-strain curves, identified by the use or omission of lubricants. Several laboratories did not report lubricant use. Table 3 identifies the lubricants used. Three laboratories used no lubricant, and their stress-strain curves are the lowest in the collection. Figure 12 plots the reported modulus, $E$, and yield strength, $Y S(0.2 \%$ offset $)$, identified by lubricant use. The average yield strength from the three laboratories that did not use lubricant was $10.6 \mathrm{MPa}$ lower $(3.1 \%)$ than the average of the laboratories that lubricated the specimen. Similarly the average reported elastic modulus, $E$, from the three laboratories was $4.1 \mathrm{GPa}(5.7 \%)$ smaller. Table 8, an analysis of variance, shows that the reported yield strength, $Y S(0.2 \%$ offset $)$, and modulus, $E$, are both significantly different for the lubricated and unlubricated cases. 


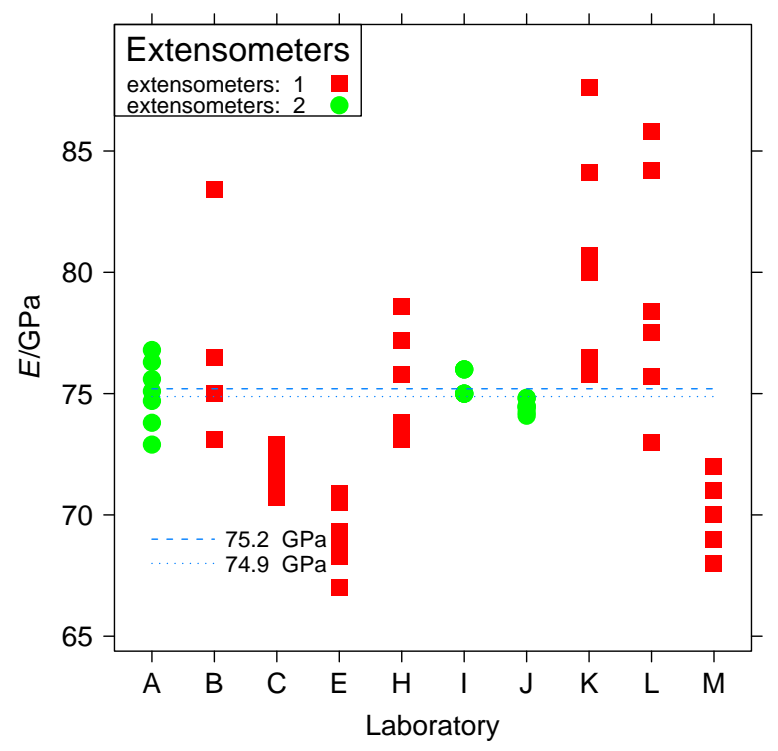

(a) Modulus

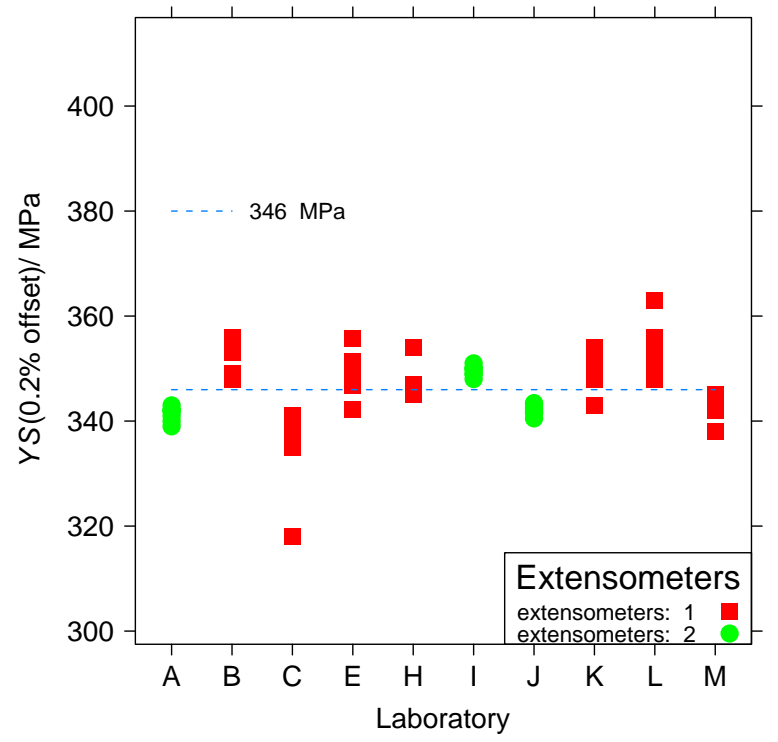

(b) $Y S(0.2 \%$ offset $)$

Figure 10: Reported (a) modulus and (b) $0.2 \%$ offset yield strength, $Y S(0.2 \%$ offset $)$, identified by number of extensometers used. 


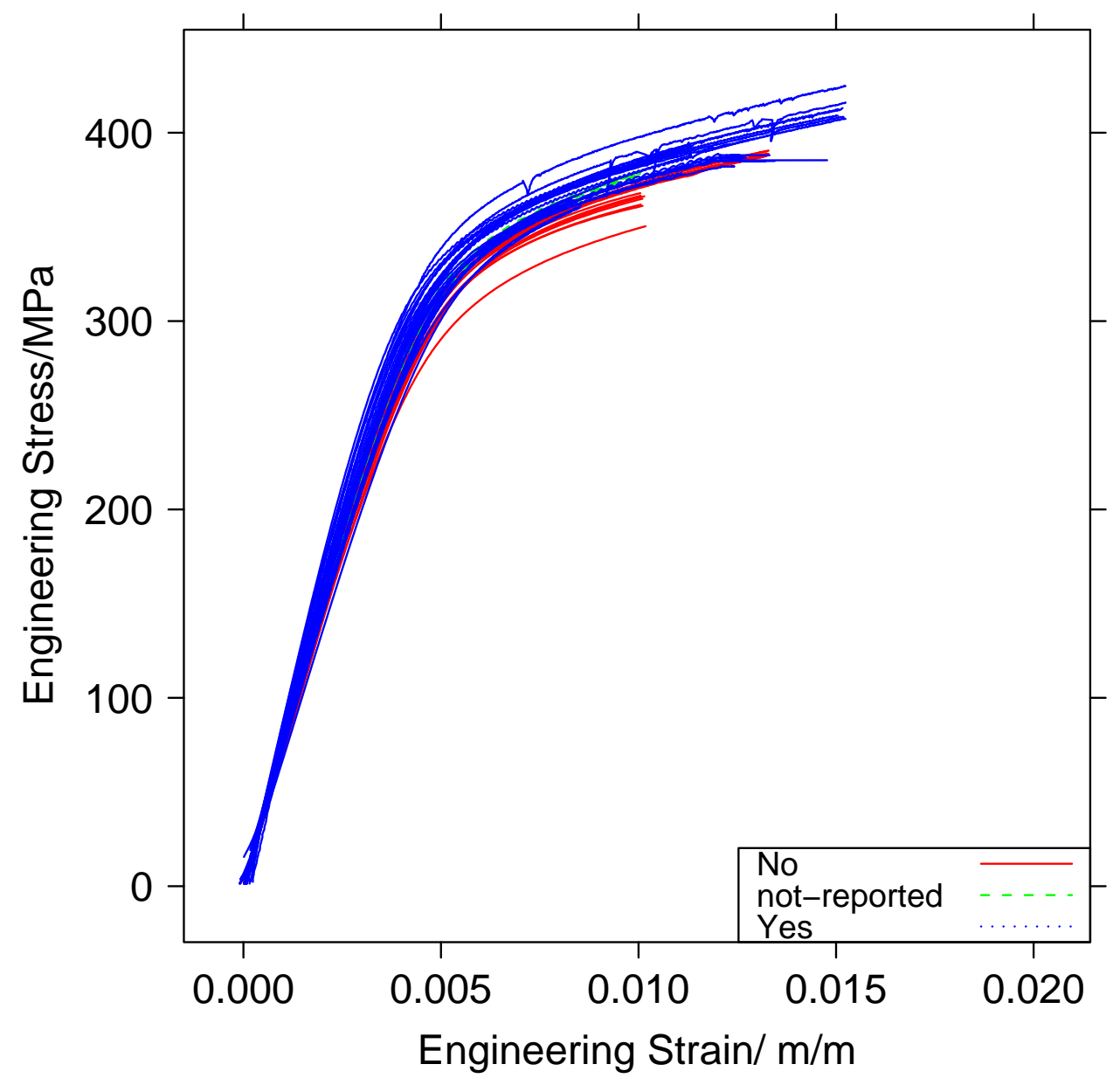

Figure 11: Effect of lubricant on stress-strain behavior. 


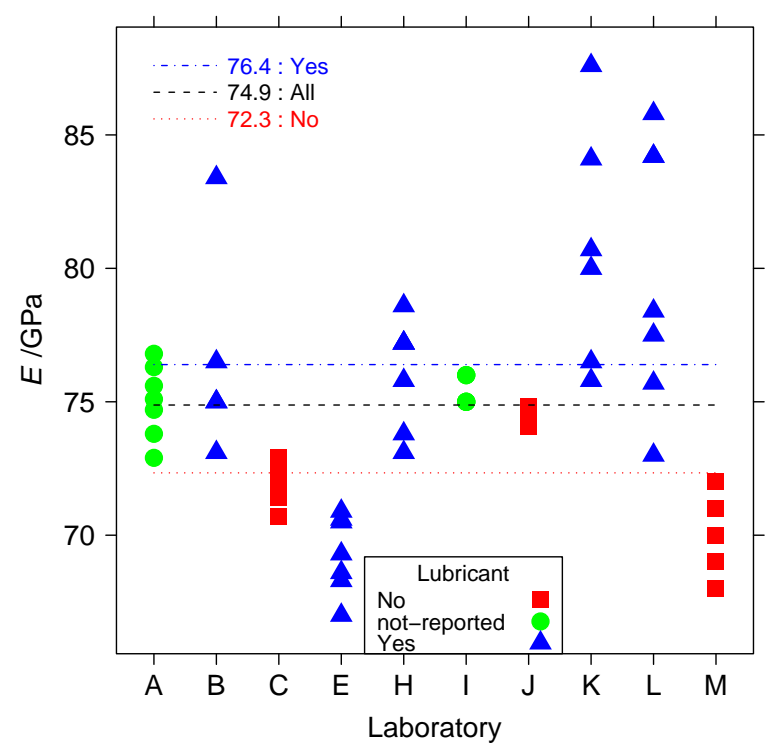

(a) Modulus, $E$

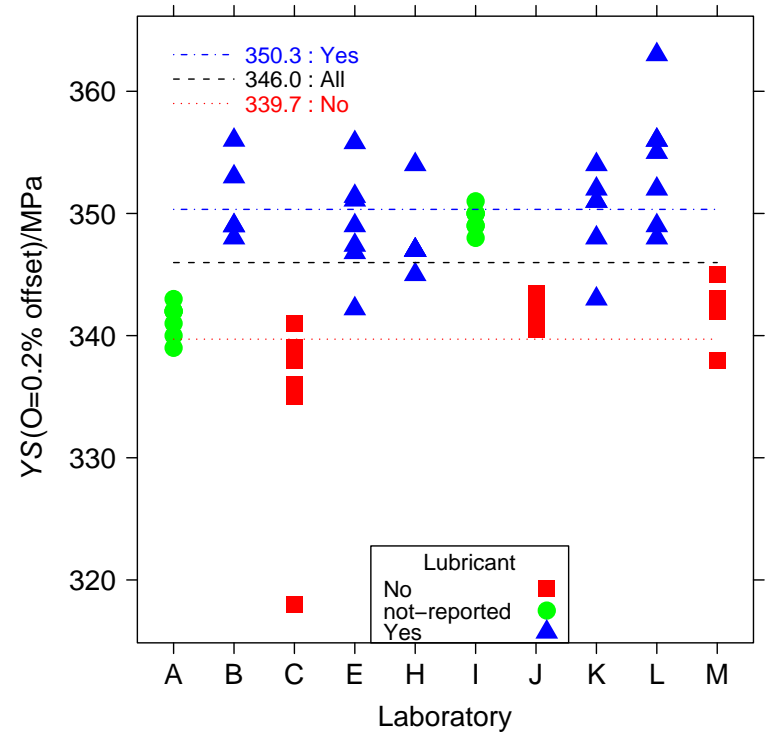

(b) Yield strength, $Y S(0.2 \%$ offset $)$

Figure 12: Effect of lubricant on (a) modulus $E$ and (b) yield strength $Y S(0.2 \%$ offset $)$. Dashed lines are the mean values for all data, including "not-reported," not lubricated ("No") and lubricated ("Yes") tests. 
Table 8: Analysis of variance tables for assessing the effect of lubrication on modulus and yield strength.

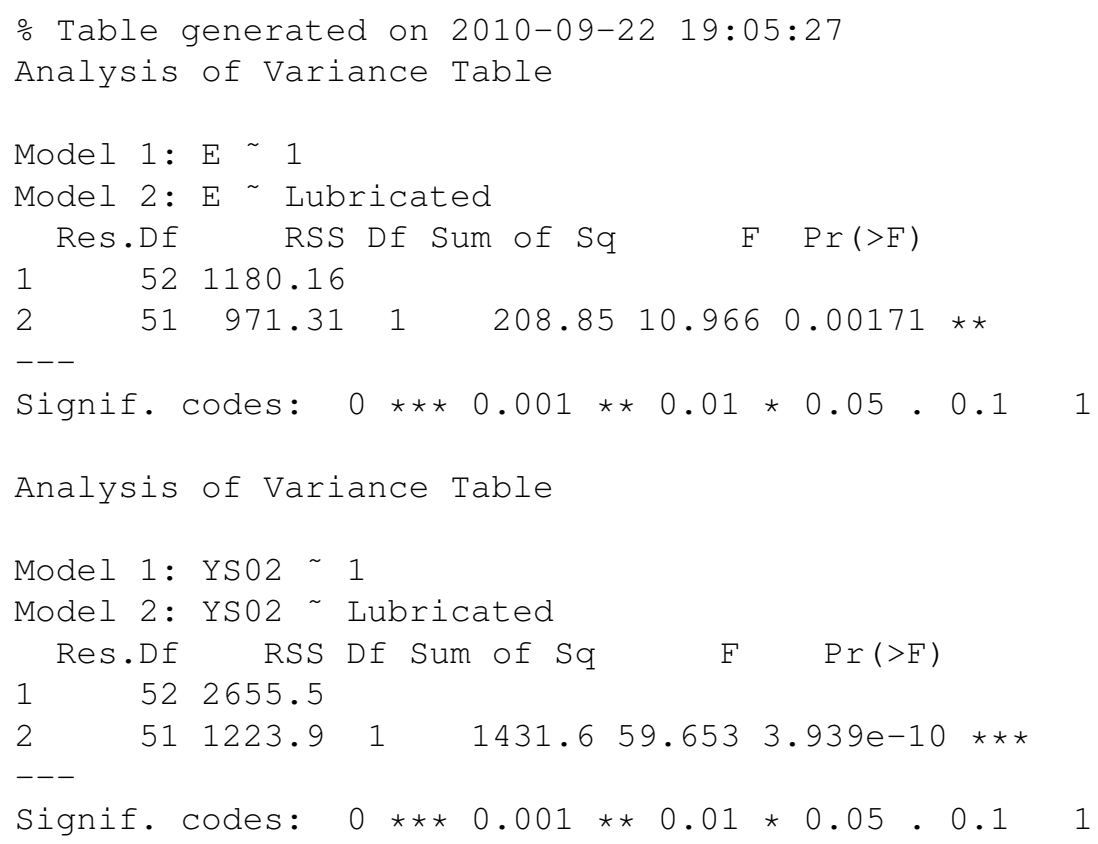

Key to parameters in table:

$\mathrm{E}: E$, elastic modulus

YS 02: YS(0.2\% offset), $0.2 \%$ offset yield strength

Data from laboratories that did not report the lubrication are omitted. Model 1 is the mean value of of the parameter, and model 2 computes the mean value for the lubricated ("Yes") and unlubricated ("No") cases.

Since most laboratories used an extensometer with a gauge length $G=25.4 \mathrm{~mm}$ on the test specimen, Fig. 2, with length $l \approx 48 \mathrm{~mm}$ and diameter $d=12.7 \mathrm{~mm}$, the end of the test specimen is approximately one test specimen diameter away from the extensometer contact point. That distance complies with the requirements of E9, and should minimize the effect of the non-uniform stress caused by friction at the specimen ends. No study has examined the sensitivity of the strain measurement to the non-uniform stress at the end of the specimen, but the existence of non-uniform stresses caused by friction is well known [29]. Finite element analysis (FEA), using the commercial finite-element modeling software Abaqus/Standard 6.10 [30], was used to analyze the effect of friction and gauge length on the response of the specimen. By exploiting the axial and radial symmetry of the specimen and platens, it was only necessary to model the upper-right 


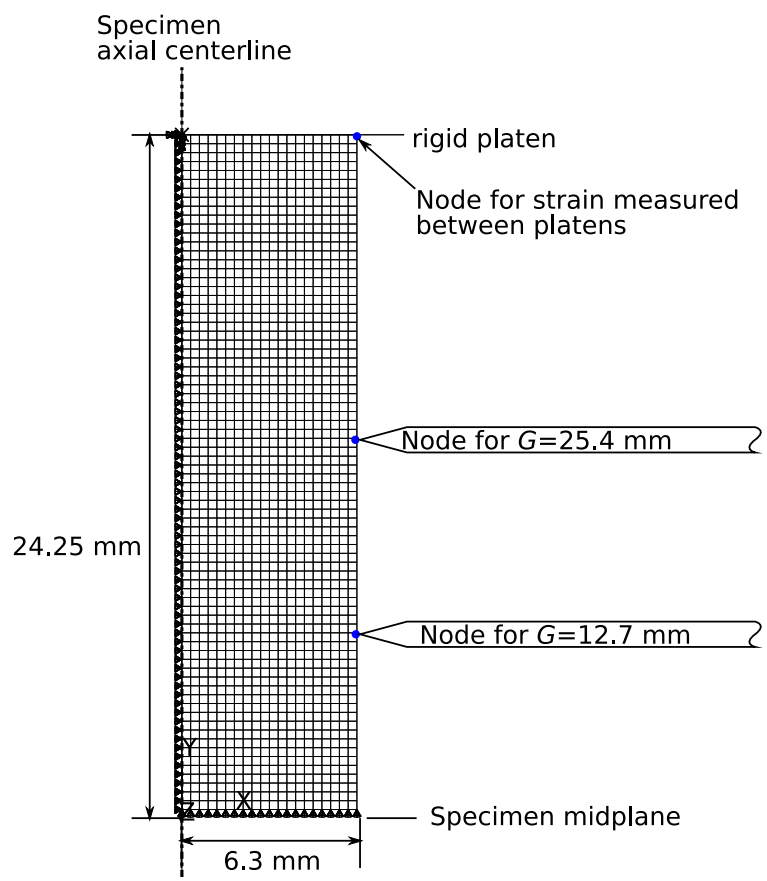

Figure 13: Finite element mesh and boundary conditions of the upper-right quadrant of the test specimen.

quadrant the specimen with radius $r=6.3 \mathrm{~mm}$ and length $l=24.25 \mathrm{~mm}$. The specimen mesh, Figure 13, was constructed with 1542 quadrilateral four-node axi-symmetric (CAX4) elements. The platens were modeled as non-deforming, rigid planes of infinite elastic modulus. Roller boundary conditions were applied on the axial centerline and the specimen midplane. The specimen material was modeled as a homogeneous elasticplastic time-independent material exhibiting strain hardening. The plastic deformation was modeled by the $J_{2}$ (or von Mises) flow plasticity theory with isotropic hardening.[30] The uniaxial stress-strain curve was taken from specimen LT-14 of the experimental results, down-sampled to 58 points, with the Young's modulus set to the accepted value $E=75.2 \mathrm{GPa}$, and Poisson's ratio $\nu=0.33$. This material model yields at a true stress $\sigma=190.4 \mathrm{MPa}$ at a true strain $\epsilon=0.0026$, and not at the value of the $0.2 \%$ offset value $Y S(0.2 \%$ offset $)=343.4 \mathrm{MPa}$. All of the stress-strain curves, Fig. 4 a, exhibited this behavior.

Two limiting cases of zero friction and complete friction at the specimen-platen interface were modeled. The simulation was performed by pushing the rigid platen increasingly to displacement of $0.485 \mathrm{~mm}$, which is $e=0.02$ deformation for the zero friction case. The effect of extensometer gauge length was tested by following the axial displacement of two nodes, Figure 13 , located $l=6.35 \mathrm{~mm}$ and $l=12.7 \mathrm{~mm}$ above the center 
plane of the specimen. These nodes correspond to the contact points of extensometers with $G=12.7 \mathrm{~mm}$ and $G=25.4 \mathrm{~mm}$ respectively. To calculate the stress-strain behavior, the force on the platen, the displacement of the platen, the displacement of the two extensometer contact points and a surface corresponding to the length between the platens, see Figure 13, were recorded. The stresses were calculated from the measured radii at those points.

Figure 14 shows the computed true stress-strain curves for strain measures across three gauge lengths ( $G=12.7 \mathrm{~mm}, G=25.4 \mathrm{~mm}$, and $G=48.5 \mathrm{~mm}$-across the loading platens) and for the two limiting friction cases: frictionless $(f=0)$ and perfect friction $(f=1)$. It also shows the true stress-strain curve used as the input model. In the figure, the true stresses, are calculated from the load $P$ and the instantaneous area, $A$, by by assuming conservation of volume in deformation:

$$
A_{0} l_{0}=A l
$$

where $A_{0}$ and $l_{0}$ are the original area and gauge length respectively. This calculation mimics what would be done in analysis of an actual experiment, where the instantaneous load-bearing area, $A$, is calculated from the strain. For the frictionless case, all the strain measures yield the same stress-strain behavior as the input model, as they should. For the case of perfect friction, $f=1$, the strains measured across the two extensometer gauge length, $G=12.7 \mathrm{~mm}$ and $G=25.4 \mathrm{~mm}$ differ by less than $0.5 \mathrm{MPa}$ from each other and from the frictionless cases. The difference between the average of yield strengths measured by laboratories that lubricated and those that did not was was twenty times this large: $\Delta Y S(0.2 \%$ offset $)=10.4 \mathrm{MPa}$, Figures 11 and 12 . The true stress calculated from the displacement of the loading platen, a common method that use the displacement of the actuator, corrected for machine compliance, is about $6 \mathrm{MPa}$, or $1.4 \%$, above all the other curves. Note that no laboratory measured strain this way; each laboratory used an extensometer on the test specimen, with contact points remote from the test specimen end faces. The agreement between the extensometer methods for the frictionless and complete friction cases eliminates friction as the source of the difference in yield behavior between the laboratories that lubricated and those that did not.

The finite-element analysis also determined the evolution of the stress distributions in the test specimen. Figure 15 shows the von Mises stress evolution for four strains. Stresses less than the yield stress of the material model, $\sigma=190.4 \mathrm{MPa}$, are shown in white. Consistent with other analyses [29, 6], a non-deforming cap forms at the test specimen end. As the specimen deforms, a region of slightly higher stress develops that extends just into the region that the longer, $G=25.4 \mathrm{~mm}$ extensometer samples. Figure 16 shows the evolution of the shear stress, $\sigma_{12}$ for the same four strains. The bulk of the test specimen has zero shear stress. Only at the test specimen ends, where friction constrains the deformation, does shear strain develop. 


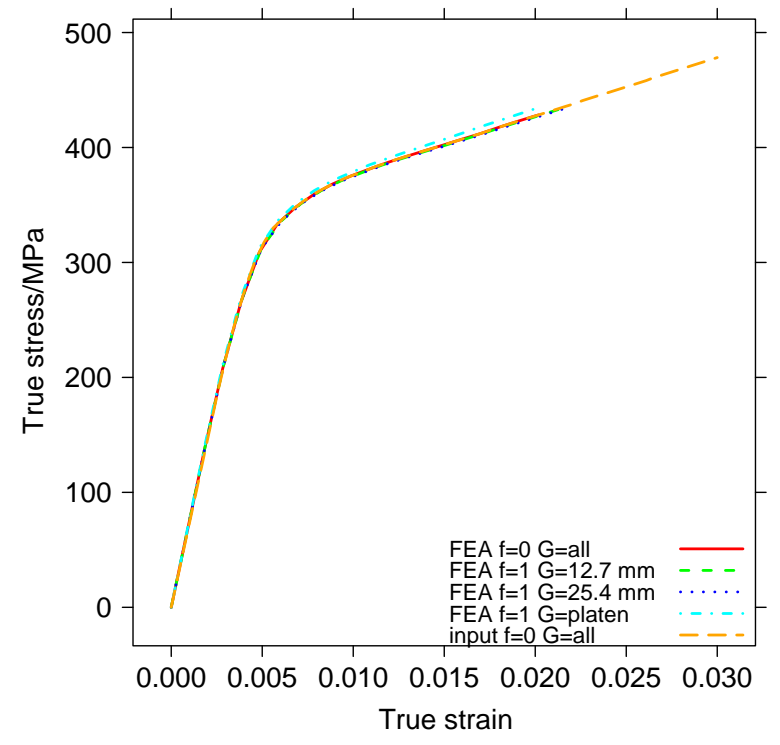

(a) Full curve

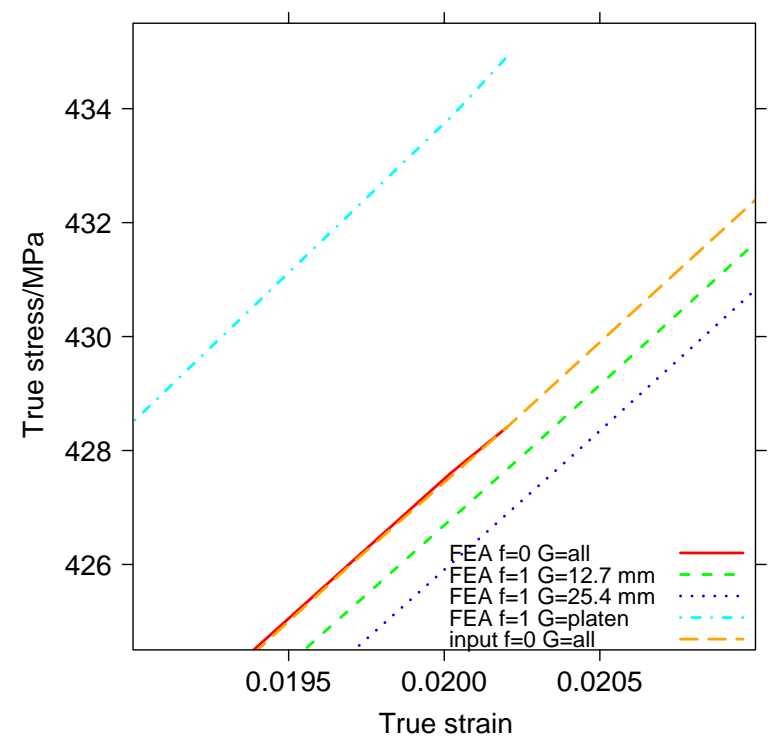

(b) Expanded section

Figure 14: Computed true stress-strain curves for the cases of frictionless $(f=0)$ and perfect friction $(f=1)$ and different gauge lengths, $G$ : (a) full curve, and (b) expanded section that shows the small differences between the results at large strain. 


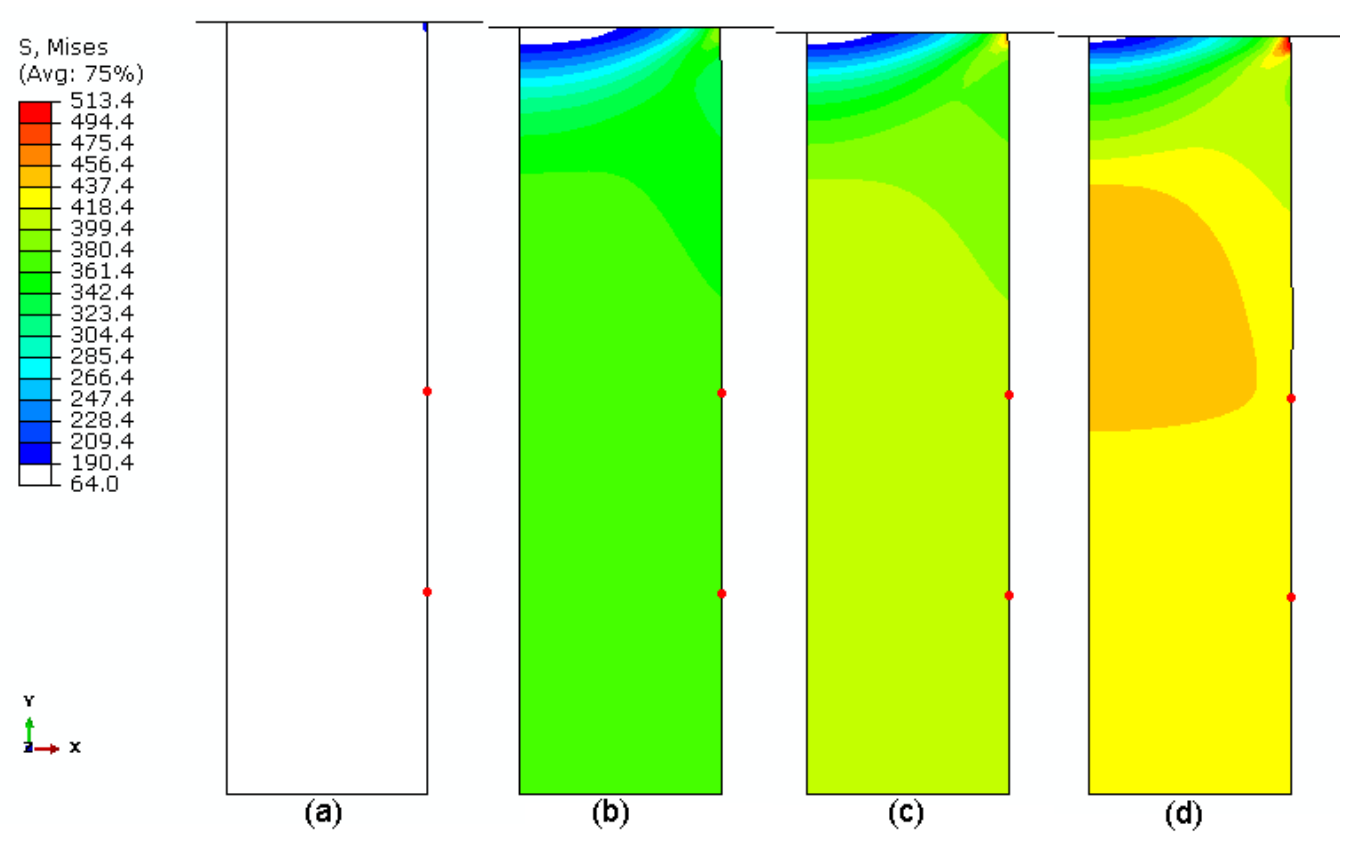

Figure 15: Von Mises stress distribution in the upper-right quadrant of the test specimen for four true strains: (a) $\epsilon=0.002$, (b) $\epsilon=0.008$, (c) $\epsilon=0.015$, and (d) $\epsilon=0.022$, measured from the $G=12.7 \mathrm{~mm}$ extensometer for the case of perfect friction.

\subsection{Elastic Modulus}

The elastic modulus measured in the test is very sensitive to the alignment and sensitivity of the test setup. As a result, ASTM E 9 [2] requires that laboratories validate their compression test fixture by measuring the elastic modulus of aluminum alloy 2024-T4 bar, according ASTM E 111 [31] and obtaining measurements on five consecutive specimens to within $5 \%$ of a stated value, $E=73.8 \mathrm{GPa}$. The behavior of the reported elastic modulus should be a good indicator of the quality of the compression test facility.

The interlaboratory study did not require laboratories to revalidate their test setups, but they did report the measurements of elastic modulus, Figure 5, made during the compression tests of this study. Most of the laboratories only used a ASTM E 83 [32] Class B-2 extensometer, see Table 3 , rather than the roughly twice-as-accurate class B-1 extensometer required by ASTM E 111 [31] when elastic modulus is the primary parameter to be determined. But because the primary parameter to be determined was the yield strength, E 9 Section 9.2 permits the use of the class B-2 extensometer.

The laboratories had wide latitude in the method to determine the elastic modulus to report. To reduce the variability due to the interpretation of the individual laboratory, and to put each modulus measurement on a consistent basis, we reanalyzed each stressstrain curve to estimate the elastic modulus using a technique [33] based on the method 


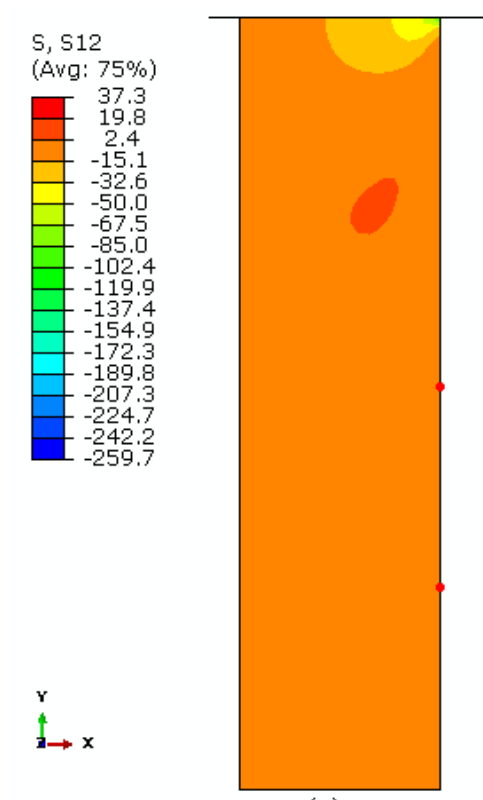

(a)

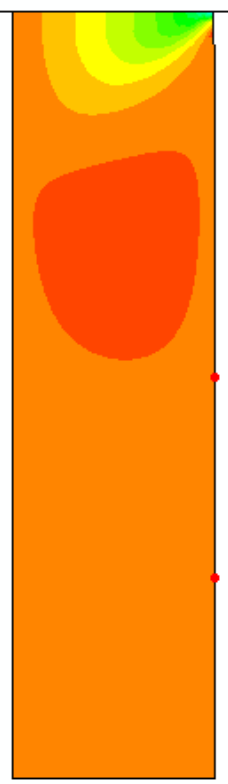

(b)

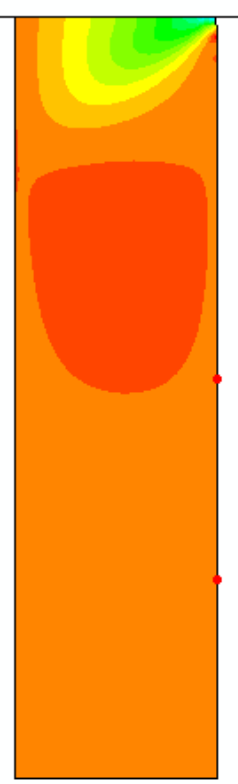

(c)

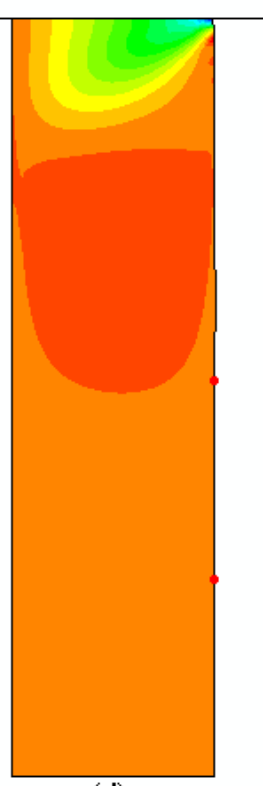

(d)

Figure 16: Shear stress distribution in the upper-right quadrant of the test specimen for four true strains: (a) $\epsilon=0.002$, (b) $\epsilon=0.008$, (c) $\epsilon=0.015$, and (d) $\epsilon=0.022$, measured from the $G=12.7 \mathrm{~mm}$ extensometer for the case of perfect friction.

of Scibetta and Schuurmans [34]. These reanalyzed moduli are denoted by the symbol $E_{G A}$, to differentiate them from the moduli that the participants calculated and reported, denoted by $E$. In addition to estimating the modulus, the method includes some checks on the quality of the data that may be useful for laboratories that seek to improve their modulus measurement.

Many of the following plots evaluate the quality of the measurements by employing the absolute modulus error, $\Delta E_{G A}$, in a measurement, which is defined as the absolute value of the difference between the accepted modulus [25] for 2024-T351 aluminum, $E_{\mathrm{Al}}^{\mathrm{acc}}=75.2 \mathrm{GPa}$ and the calculated modulus, $E_{G A}$.

$$
\Delta E_{G A}=\left|E_{\mathrm{Al}}^{\mathrm{acc}}-E_{G A}\right|
$$

Other references [35, 36, 37, 2] recommend different values in the range $73.8 \mathrm{GPa}<$ $E<76.1 \mathrm{GPa}$, and differentiate [36] between longitudinal and transverse orientation.

Method for analysis The method consists of nine steps.

1 Find the knee of the stress-strain $(s-e)$ curve by the method of Scibetta and Schuurmans [34].

1. Find the point on the stress-strain curve $\left(e_{1}, s_{1}\right)$ closest to $s_{1}=0.05 \max (s)$ 
2. Create point $\left(e_{o}, s_{o}\right)$ where $e_{o}=e_{1}$ and $s_{o}=0.2 \max (s)$.

3. Find the point on the stress-strain curve $\left(e_{t}, s_{t}\right)$ that is on a line drawn through $\left(e_{0}, s_{0}\right)$ that is tangent to the stress-strain curve.

2 Truncate the stress-strain data at $\left(e_{t}, s_{t}\right)$ and normalize by these values. Retain the maximum values of the test record: $\left(e_{\max }, s_{\max }\right)$.

3 Check digital resolution, $\delta$, of stress and strain. The digital resolution should be $\delta_{e}<\frac{3}{2^{12}} \frac{x_{\max }}{e_{t}}$ and $\delta_{s}<\frac{3}{2^{12}} \frac{x_{\max }}{s_{t}}$. No more than more than $25 \%$ of points should have zero stress or strain change from the previous point.

4 Use the Scibetta-Schuurmans [34] algorithm to determine optimum fit window and calculate the slope, which is the elastic modulus $E_{G A}$, in normalized form. The Scibetta-Schuurmans algorithm finds the optimal region for determining the modulus by performing a linear regression of stress on strain on every possible subset of data in the region $e_{o}<e<e_{t}$ that contains at least $20 \%$ of the data. The regression with the lowest residual standard deviation is the optimum fit. In some cases, more than one million fits were evaluated for each stress-strain curve.

5 Check for excessive noise in optimum fit window, defined as the standard error of the regression in step 4: $s_{j}$ defined in Table 6 where $n$ is the number of stress-strain pairs in the optimal region, $Y_{i j}$ is the normalized stress evaluated at point $j$, and $\bar{Y}_{j}$ is the predicted normalized stress from the fit to the optimal region. Perform the complementary regression of strain upon stress as well. In both cases, the standard error in strain or stress should not be greater than 0.01 .

6 Extend the range of fit to include all stress points whose deviation from the optimal fit line is less than one times standard error computed in Step 5.

7 Refit the extended data set to determine modulus, $E_{G A}$.

8 Examine the shape of the stress and strain residuals as a function of strain in the extended fit. If the slope of the residuals in the first or fourth quartile of the extended range is more than 0.05 , the data exhibit excessive curvature. At least five points must exist in each quartile to evaluate this curvature.

9 Check that the stress range of the optimal fit is greater than $0.4 s_{t}$.

The method employs four metrics to determine the quality of the modulus:

- Data quality 1: digital stress and strain resolution should be sufficient (Step 2)

- Data quality 2: strain or stress signal should not have excessive noise (Step 5)

- Fit quality 1: the stress and strain residuals in extended data range should not have excessive curvature (Step 8) 
- Fit quality 2: the size optimal fit range, $R_{f}$, should be greater than or equal to $40 \%$ of the total range used to determine the modulus (Step 9)

The rest of this section will examine the results of the modulus measurement, $E_{G A}$, using these four quality metrics.

Data Quality 1: sufficient digital resolution Figure 17 summarizes the strain and stress resolution. Estimating the digital resolution of a data set post-test is difficult, and the interested reader should consult the original reference by Graham and Adler [33]. To create the figure, the digital resolution was estimated from the data set by taking the absolute value of the difference of each sequential pair of stress and strain points, for example $\left|s_{i}-s_{i+1}\right|$. Those differences, expressed in units of $\delta$ from step 3, were binned to create a histogram. If too many of the points show no change between reading, or if the most frequent change is many times larger than the digital resolution, $\delta$ defined in Step 3, the stress-strain curve may have insufficient digital resolution. This condition could arise, for example, if a load cell were used near the very lower limit of its working range, or if the analog-to-digital converter had insufficient precision. Figure 17 plots the index of the bin with the maximum fraction of the data, in units of $\delta$, defined in step 3, against the fraction of the points in the "zeroth" bin, which is the fraction of points where the stress or strain value did not change between readings. The symbols show the fraction of the points in the bin of maximum fraction, broken into two groups: those where the bin of maximum fraction contained less than $25 \%$ of the data $((0,25])$ and those that contained more than $25 \%$ of the data $((25, \mathrm{Inf})$. The method identifies experiments with insufficient digital resolution as those where the bin of maximum fraction is greater than 3 and either the fraction in the zeroth bin is $>25 \%$ or the fraction in the bin of maximum fraction is $>25 \%$. The first condition is identified by the dashed lines. The second "or" condition comprise those points identified by green circles with $y$ value greater than 3 . No experiment demonstrated insufficient digital resolution.

Data Quality 2: excessive noise Excessive noise in the strain or stress signal will degrade the quality of the measured modulus. The method identifies experiments with excessive noise in these signals as ones in which the standard error of the fit is greater than 0.01 . Figure 18 plots the standard error of the fit for both strain and stress by laboratory. The symbols identify three levels of modulus error, Eq. 10. The noise in all the experiments was sufficiently low. No obvious relation exists between the absolute modulus error, $\Delta E$, and either the standard error of stress or strain.

Fit Quality 1: Excessive curvature in extended data set Some metric of the curvature of the optimal fit range is necessary, since the method only selects the best fit over an optimal region. That fit might still be poor. One method for examining the quality of the fit is to examine the deviation from the fit line in the first and fourth quartiles of the optimal range. Curvature of the stress-strain record frequently appears this way. If the slope of the residuals vs. strain in the outer quartiles is greater than $5 \%$ of the slope in the optimal region, the curvature of the fit is deemed excessive. 


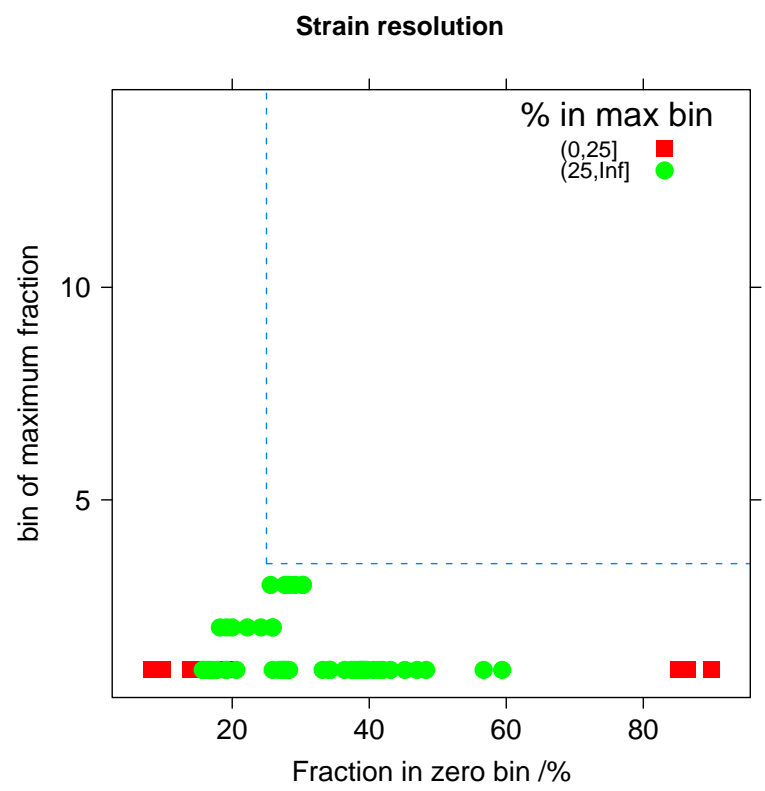

(a) strain resolution

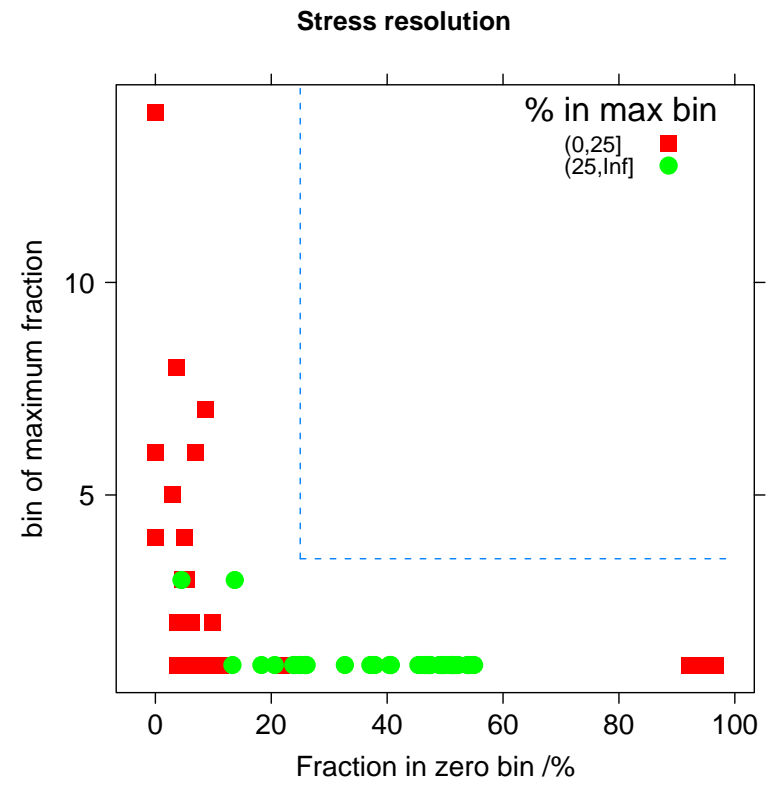

(b) stress resolution

Figure 17: (a) Strain and (b) stress data resolution. Dashed lines enclose the region of insufficient resolution. Symbols denote the fraction of points in the bin of maximum fraction. 


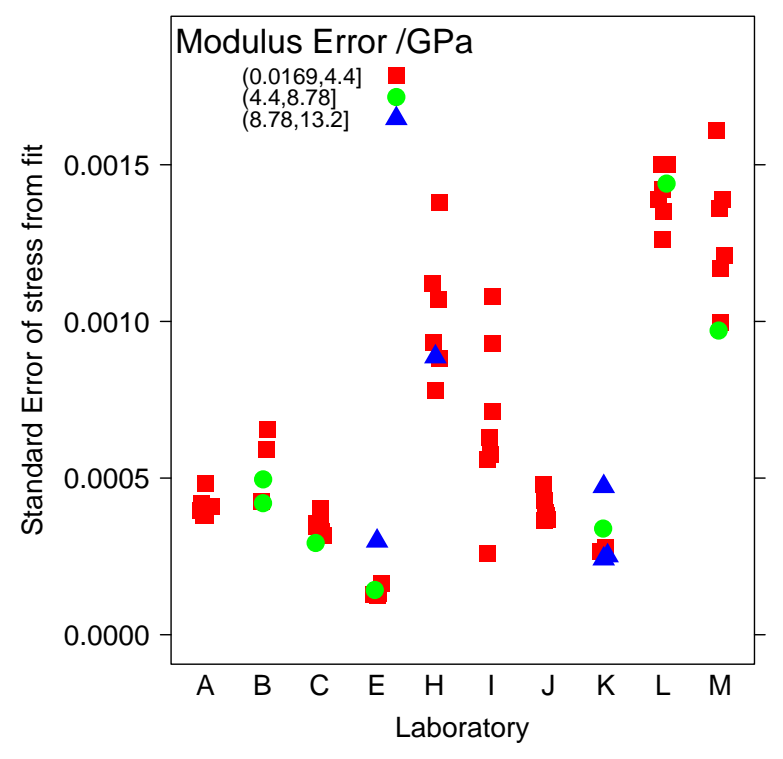

(a) strain noise

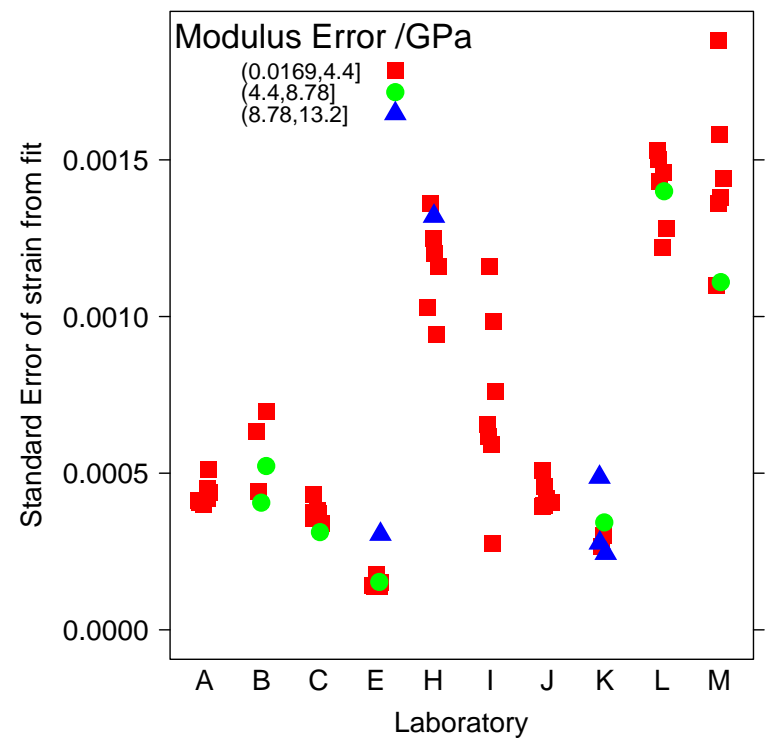

(b) stress noise

Figure 18: Noise in calculated modulus based on (a) strain, and (b) stress, calculated in Step 5. Symbols denote three increasing levels of absolute modulus error, Eq. 10. All measurements are below the acceptance limit of 0.01. Data have been jittered to prevent over-plotting of points. 
Figure 19 shows the slope of the residuals in the outer quartiles. Different symbols show the level of absolute error of the elastic modulus, Eq. 10. All but one of the tests fall inside the $\pm 5 \%$ limits. In addition, linear regression of the absolute modulus error against the absolute value of the residual slope reveals no relationship.

Fit Quality 2: Final fit range The second measure of the quality of the fit to determine the elastic modulus, $E_{G A}$, is the size of the optimal fit range, $R_{f}$. Figure 20 plots the absolute modulus error, Eq. 10, against the fraction of the range of original stress data. The dashed line is the boundary of the minimum acceptable limit $R_{f} \geq 0.4$. The absolute modulus error, Eq. 10 increases as the size of the fit region decreases, as expected, and the boundary between the two regions lies at the chosen final fit range minimum $R_{f}=$ 0.4 . The mean error for tests with fit region $R_{f}<0.4$ is 2.5 times larger (4.88 GPa vs. $1.95 \mathrm{GPa}$ ) than that from the acceptable region.

Conclusions from elastic modulus analysis Of the quality metrics, the size of the final fit range is the best predictor of overall quality of the modulus measurement, and the level chosen, $R_{f} \geq 0.4$, is a good metric for identifying potential problems with modulus measurement.

\section{Conclusions}

Five conclusions can be drawn from this study.

- The repeatability of yield strength determined from compression tests conducted according to ASTM E9 can be expected to be about $1.1 \%$ of the mean value, $c v_{r}=$ 0.011 , Figure 6 and Table 5 .

- The reproducibility of yield strength determined from compression tests conducted according to ASTM E9 can be expected to be about $2 \%$ of the mean value, $c v_{R}=$ 0.020 , Figure 6 and Table 5 .

- Despite the perceived difficulties with alignment in compression, the repeatability and reproducibility of the compression test was among the best measured for uniaxial tests, Figure 9 .

- Using two diametrally opposed extensometers instead of a single extensometer can improve the precision of the strain measurement by more than two times, Figure 10.

- If the final fit range for estimating the modulus is less than $40 \%$ of the elastic region, the modulus measurement is frequently in error, Figure 20

In addition, although the reported data indicated that yield strengths measured on unlubricated conditions were $3.1 \%$ lower than those measured using lubricated specimens, Fig. 12, a finite-element analysis of the deformation that incorporated test-specimen-end friction did not identify any mechanism by which friction could caused the discrepancy. 


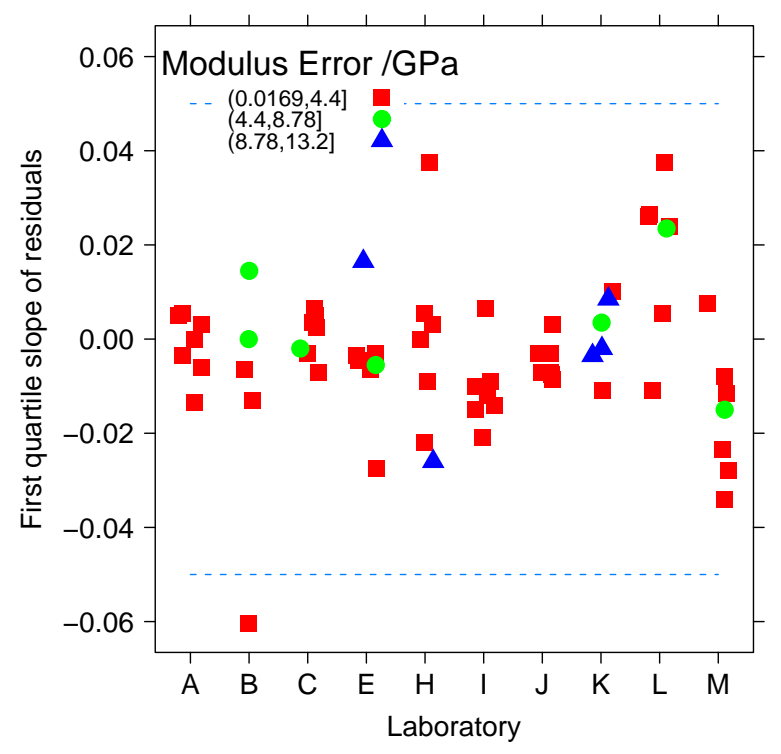

(a) 1st quartile slope

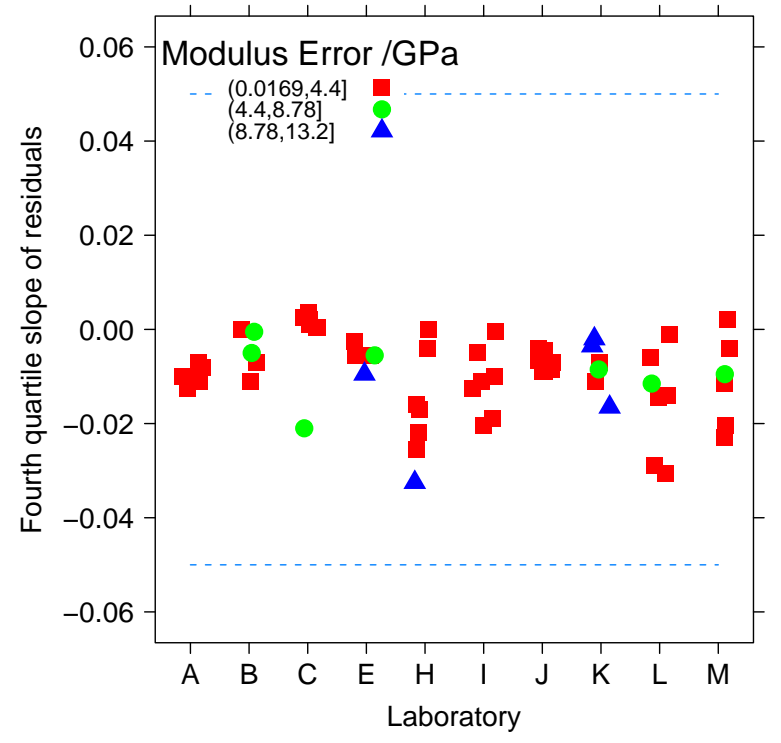

(b) 4th quartile slope

Figure 19: Slope of residuals in the (a) 1st, and (b) 4th quartile of the extended fit for modulus. Symbols denote three increasing levels of absolute modulus error, Eq. 10, Dashed lines denote the acceptance limit Data have been jittered to prevent over-plotting of points. 


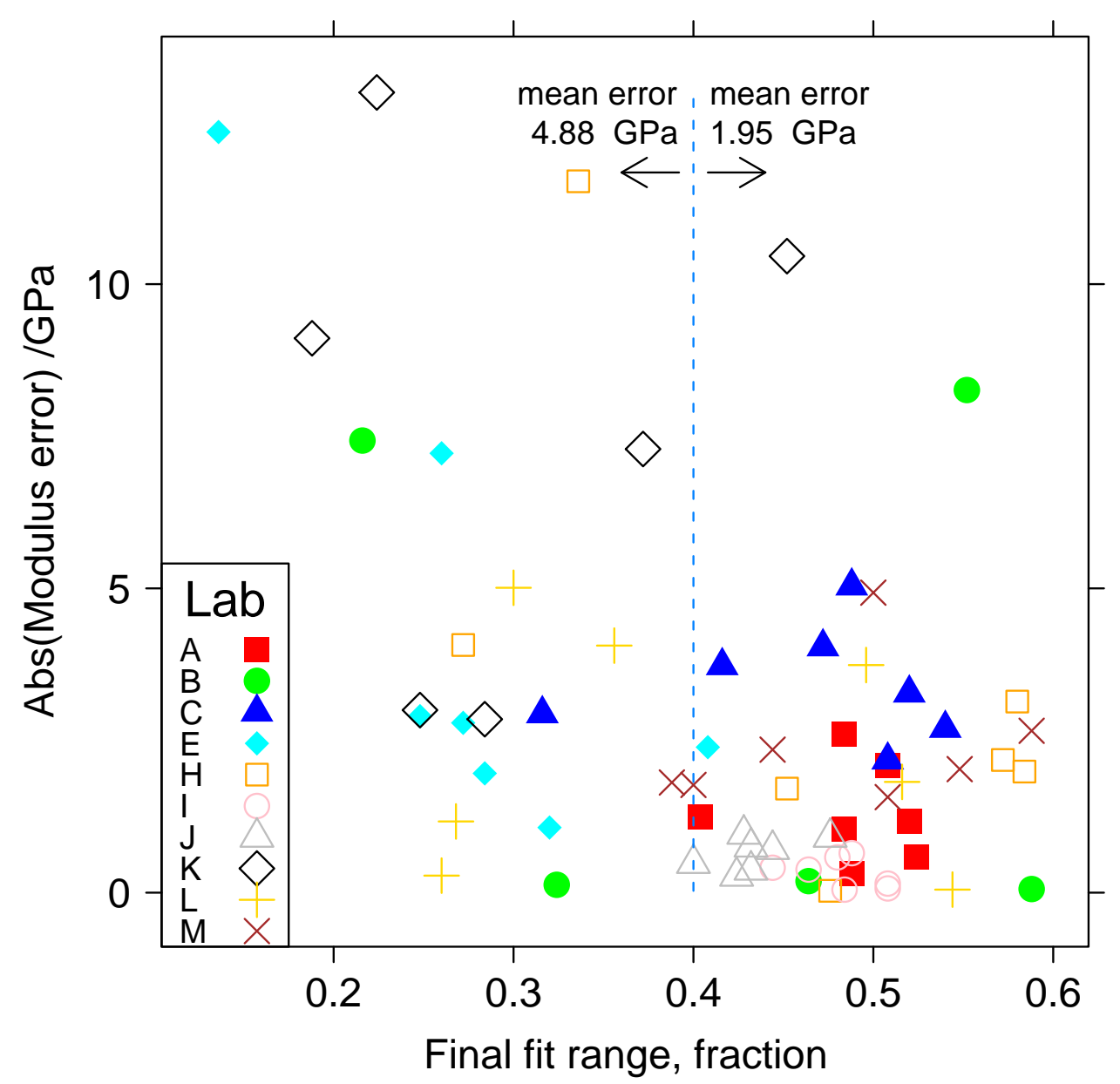

Figure 20: Absolute error in modulus, Eq. 10, as a function of the fraction of the final fit range, $R_{f}$, used to calculate the modulus. Symbols identify the different laboratories. Points to the left of the dashed line are deemed to have insufficient fit range. 


\section{Author contributions}

William Luecke supervised the interlaboratory study and analyzed the reported modulus and yield strength data. Stephen Graham and Matthew Adler analyzed the stress-strain curves to recalculate the modulus and the associated data and fit qualities. Li Ma conducted the finite element analysis of the specimen deformation under frictionless and perfect friction.

\section{Acknowledgments}

The authors could not have completed this study without the generous donation of the testing services of the participants, including those who volunteered, but ultimately could not complete the testing in the brief time allotted: Ray Schiltz (AADFW, Inc), Rich Brazill (Alcoa), Rick Kapaun (Exova), Bill Swartz (Constellation Technology Corp.), I. Ahmed (Dickson Testing Company Inc.), James Hartman (Honeywell Aerospace), Hugh MacGillivray (Imperial College Mechanical Engr.), Matt Webb (MAR-TEST, Inc. (Cincinnati)), Frank Worpenberg (MAR-TEST, Inc. (Stuart)), Ken Broenner (Metcut Research Inc.), Dennis Galloway (Stork Climax Research Services), and Mike Self (Westmoreland Mechanical Testing).

WEL thanks the other two members of the organizing team, Rich Brazill and James Hartman for their assistance. Rich Brazill supplied the aluminum plate, the test specimen blanks, and the test specimen assignments.

\section{References}

[1] ISO. Hardmetals-compression test. Standard 4506:1979, International Organization for Standardization, 1979. Available from: http://www.iso.org/iso/iso_catalogue/ catalogue_tc/catalogue_detail.htm?csnumber=10402.

[2] ASTM International. Standard test methods of compression testing of metallic materials at room temperature. Standard E9-09, ASTM International, W. Conshohocken, $\mathrm{Pa}, 2009$. doi:10.1520/E0009-09.

[3] Howard A. Kuhn. Uniaxial compression testing. In Howard Kuhn and Dana Medlin, editors, Mechanical Testing and Evaluation, volume 8 of ASM Handbook, pages 143-151. ASM International, Materials Park, Ohio, USA, 2000.

[4] R. Chait and C. H. Curll. Evaluating engineering alloys in compression. In A. K. Schmieder, editor, Recent Developments in Mechanical Testing, ASTM Special Technical Publication 608, pages 3-19. American Society for Testing and Materials, 1975. doi:10.1520/STP608-EB

[5] J. K. Banerjee. Barreling of solid cylinders under axial compression. Journal of Engineering Materials and Technology, 107(2):138-144, 1985. doi:10.1115/ 1.3225789 . 
[6] William T. Carter Jr. and Daeyong Lee. A finite element analysis of cylinder and ring compression and its experimental verification. Computers \& Structures, 21(1-2):1 19, 1985. doi:10.1016/0045-7949(85) 90225-1.

[7] Maurice Cook and Eustace C. Larke. Resistance of Copper And Copper Alloys to Homogeneous Deformation in Compression. Journal of the Institute of Metals, 71(12):371-390, 1945.

[8] J. S. Gunasekera, J. Havranek, and M. H. Littlejohn. The effect of specimen size on stress-strain behavior in compression. Journal of Engineering Materials and Technology, 104(4):274-279, 1982. doi:10.1115/1.3225076.

[9] T. C. Hsü. A study of the compression test for ductile materials. Materials Research and Standards, 12(9):20, 1969.

[10] Syed Kamaluddin, J. Babu Rao, M. M. M. Sarcar, and N. R. M. R. Bhargava. Studies on flow behavior of aluminum using vision system during cold upsetting. Metallurgical and Materials Transactions B, 38(4):681-688, 2007. doi: 10.1007/s11663-007-9070-1.

[11] Shiro Kobayashi. Deformation characteristics and ductile fracture of 1040 steel in simple upsetting of solid cylinders and rings. J. Eng. Ind. Trans. ASME, 92:391-399, 1970. doi:10.1115/1.3427752.

[12] M. L. Lovato and M. G. Stout. Compression testing techniques to determine the stress/strain behavior of metals subject to finite deformation. Metallurgical and Materials Transactions A, 23(3):935-951, 1992. doi:10.1007/BF02675569.

[13] A. T. Male. Variations in friction coefficients of metals during compressive deformation. J. Inst. Metals, 94(4):121-125, 1966.

[14] John Mescall, Ralph Papirno, and James McLaughlin. Stress and deformation states associated with upset tests in metals. In Richard Chait and Ralph Papirno, editors, Compression Testing of Homogeneous Materials and Composites, ASTM Special Technical Publication 808, pages 7-23. American Society for Testing and Materials, 1983. A symposium sponsored by ASTM Committee E-28 on Mechanical Testing Williamsburg, VA 10-11 March, 1982. doi:10.1520/STP 808-EB.

[15] Ralph Papirno, John Mescall, and Anna M. Hansen. Fracture in axial compression tests of cylinders. In Richard Chait and Ralph Papirno, editors, Compression Testing of Homogeneous Materials and Composites, ASTM Special Technical Publication 808, pages 40-63. American Society for Testing and Materials, 1983. A symposium sponsored by ASTM Committee E-28 on Mechanical Testing Williamsburg, VA 1011 March, 1982. doi:10.1520/STP 808-EB. 
[16] K. K. Ray and A. K. Mallik. On the Determination of Flow Properties from Compression Tests. Metallurgical Transactions A-Physical Metallurgy And Materials Science, 14(1):155-156, 1983. doi:10.1007/BF02643750.

[17] J. A. Schey, T. R. Venner, and S. L. Takomana. Shape changes in the upsetting of slender cylinders. Journal of Engineering for Industry, 104(1):79-83, 1982. do i : $10.1115 / 1.3185802$.

[18] R. L. Woodward. A note on the determination of accurate flow properties from simple compression tests. Metallurgical and Materials Transactions A, 8(11):18331834, 1977. doi:10.1007/BF02646893.

[19] ASTM International. Form and Style for ASTM Standards. ASTM International, 100 Barr Harbor Drive, PO Box C700, West Conshohocken, PA 19428-2959, March 2009. Available from: http://www.astm.org/COMMIT/Blue_Book.pdf.

[20] ASTM International. Interlaboratory study to establish a precision statement for standard test methods of compression testing of metallic materials at room temperature. Research Report E28-1042, ASTM International, 100 Barr Harbor Dr, West Conshohocken, Pa, Nov 2009. Available from: http://www.astm.org/DATABASE. CART/RESEARCH_REPORTS/RR-E28-1042_691.htm.

[21] ASTM International. Standard practice for conducting an interlaboratory study to determine the precision of a test method. Standard E 691-09, American Society for Testing and Materials, 2009. Annual Book of ASTM Standards Vol 14.02. doi: $10.1520 / \mathrm{E} 0691-09$.

[22] ASTM International. Standard practice for use of the terms precision and bias in ASTM test methods. Standard E177-08, American Society for Testing and Materials, 2008. doi:10.1520/E0177-08.

[23] ASTM International. Directory of testing laboratories. www.astm.org/LABS/search. html, 2009.

[24] American Association for Laboratory Accreditation. Directory of accredited organizations. www.a2la.org/dirsearchnew/newsearch.cfm, 2009.

[25] US Department of Defense. Metallic materials and elements for aerospace vehicle structures. Handbook MIL-HDBK-5J, United States of America Department of Defense, Jan 2003. Available from: http://www.everyspec.com/MIL-HDBK/ MIL-HDBK+(0001+-+0099)/MIL_HDBK_5J_1\%39/.

[26] ASTM International. Interlaboratory study to establish precision statements for ASTM B557, standard test methods for tension testing wrought and cast aluminum- 
and magnesium-alloy products and B557M, standard test methods for tension testing wrought and cast aluminum- and magnesium-alloy products [metric]. Research Report E28-1004, ASTM International, 100 Barr Harbor Dr, West Conshohocken, Pa, Mar 1984. Available from: http://www.astm.org/DATABASE. CART/RESEARCH_REPORTS/RR-E28-1004_6.htm.

[27] Malcolm S Loveday, Tom Gray, and Johannes Aegerter. Tensile testing of metallic materials: A review. Technical report, National Physical Laboratory, April 2004. Project funded by the European Community under the "Competitive and Sustainable Growth" Programme (1998-2002), Project Number GRD1-2000-25021, contract Number G6RD-CT-2000-00412. Available from: www.npl.co.uk/advanced-materials/measurement-techniques/mechanical/ tensile-testing-standards-and-tenstand.

[28] ASTM International. Interlaboratory test data for E21, tests for elevated temperature tension tests for metallic materials. Research Report E28-1015, ASTM International, 100 Barr Harbor Dr, West Conshohocken, Pa, Sep 1992. Available from ASTM International Committee E28: www.astm.org.

[29] Klaus D. Debschütz, Bernhard Caspers, Gerold A. Schneider, and Gunter Petzow. Critical evaluation of the compression creep test. Journal of The American Ceramic Society, 76(10):2468-2474, 1993. doi:10.1111/j.1151-2916. 1993.tb03968.x.

[30] Dassault Systemes Simulia Corp, 166 Valley ST, Providence, RI, USA. Abaqus/Standard User's Manual and Theory Manual, version 6.10, 2010.

[31] ASTM International. Standard test method for young's modulus, tangent modulus, and chord modulus. Standard E111-04, ASTM International, W. Conshohocken, Pa, 2004. doi:10.1520/E0111-04.

[32] ASTM International. Standard practice for verification and classification of extensometer systems. Standard E83-06, ASTM International, W. Conshohocken, Pa, 2006. doi:10.1520/E0083-06.

[33] Stephen M. Graham and Matthew A. Adler. Determining the slope and quality of fit for the linear part of a test record. Journal of Testing and Evaluation, 39(2), 2011. Paper ID JTE103038. doi:10.1520/JTE103038.

[34] M. Scibetta and J. Schuurmans. Development and qualification of an algorithm for the determination of the initial linear portion of a force versus displacement record. Journal of Testing and Evaluation, 32(6):500-503, NOV 2004. doi:10.1520/ JTE12618. 
[35] J. A. Brammer and C. M. Percival. Elevated-temperature elastic moduli of 2024 aluminum obtained by a laser-pulse technique. Experimental Mechanics, 10(6):245250, 1970. doi:10.1007/BF02324097.

[36] Ralph F. Benck and Gordon L. Filbey Jr. Elastic constants of aluminum alloys, 2024T3510, 5083-H131 and 7039-T64 as measured by a sonic technique. Memorandum Report 2649, Army Ballistic Research Lab, Aberdeen Proving Ground Md, Aug 1976. Available from: http://handle.dtic.mil/100.2/ADB012953.

[37] Ralph F. Benck, Gordon L. Filbey Jr., and Jr. S.E. Allen Murray. Quasi-static compression stress-strain curves-IV, 2024-T3510 and 6061-T6 aluminum alloys. Memorandum Report 2655, Army Ballistic Research Lab, Aberdeen Proving Ground, Md, Aug 1976. Available from: http://handle.dtic.mil/100.2/ADB013221. 